Research Article

\title{
Physical and Mechanical Properties of Gypsum-Like Rock Materials
}

\author{
Sijiang Wei $\mathbb{D},,^{1,2}$ Chongyang Wang $\mathbb{D}^{1,2}$ Yushun Yang $\mathbb{D}^{3},{ }^{3}$ and Meng Wang $\mathbb{D}^{1,2}$ \\ ${ }^{1}$ School of Energy Science and Engineering, Henan Polytechnic University, Jiaozuo, Henan 454003, China \\ ${ }^{2}$ The Collaborative Innovation Center of Coal Safety Production in Henan Province, Jiaozuo, Henan 454000, China \\ ${ }^{3}$ Faculty of Architecture and Civil Engineering, Huaiyin Institute of Technology, Huai'an, Jiangsu 223001, China
}

Correspondence should be addressed to Yushun Yang; cqyysh@126.com

Received 10 February 2020; Revised 29 May 2020; Accepted 11 June 2020; Published 29 June 2020

Academic Editor: Chunshun Zhang

Copyright (C 2020 Sijiang Wei et al. This is an open access article distributed under the Creative Commons Attribution License, which permits unrestricted use, distribution, and reproduction in any medium, provided the original work is properly cited.

In the process of tunnel construction, gypsum rock is often encountered, and the volume of gypsum rock expands when encountering water, which is easy to cause the occurrence of rock fall, collapse, and other disasters, bringing serious challenges to the safe construction of the tunnel. Therefore, in this paper, four groups of samples under different moisture content are tested by ultrasonography, uniaxial compression, conventional triaxial compression, Brazilian splitting, X-ray diffraction, and SEM, and then the physical and mechanical properties of gypsum rock are studied, and the conclusion is as follows: the density of the water saturated sample, and the longitudinal wave velocity of the natural sample are the highest. Both the water saturation and dehydration conditions have a weakening effect on the remolded sample of high-strength gypsum powder. The peak intensity of the sample gradually increases with the increase of confining pressure, and the relationship between the peak intensity and confining pressure of the sample conforms to the Coulomb strength criterion. After high-temperature dehydration, the sample showed obvious plastic softening characteristics. The cohesion and internal friction angle of the sample are closely related to the water content. The cohesion is the largest in the $45^{\circ} \mathrm{C}$ dehydrated sample, the internal friction angle is the smallest in the saturated sample, whereas the cohesion is the smallest and internal friction is the largest in the high-temperature dehydrated sample. The characteristics of failure for the natural and $45^{\circ} \mathrm{C}$ dehydrated samples are almost the same and most samples show shear or sheartensile failure. The shear plane begins at the edge of the end face of the sample and exhibits a typical diagonal shear failure. The high-temperature dehydrated samples are completely broken under uniaxial and triaxial compression conditions. After highstrength gypsum powder was used to make the remolded sample, the calcium sulfate disappeared, the water content increased, and the main mineral components of the natural and saturated samples were the same. After dehydration at $45^{\circ} \mathrm{C}$, the sample began to release structural water and generate $\mathrm{SiO}_{2}$. After high-temperature dehydration, the hemihydrate gypsum continued to dehydrate and become soluble anhydrous gypsum.

\section{Introduction}

In recent years, with the rapid development of China's economy and the implementation of the strategy for the development of the western region, the construction of highway and railway tunnels in this region is facing increasing problems. In particular, anhydrite rock, which has typical softening, expansion and corrosion characteristics, is often encountered. Because of the complex deposit conditions, $\mathrm{CaSO}_{4}$ in gypsum rock is easily deliquescent into $\mathrm{CaSO}_{4} \cdot \mathrm{H}_{2} \mathrm{O}$, resulting in expansion of its volume, which can increase by $61 \%$ [1]. If the understanding of gypsum rock is not clear, serious safety problems, such as roof fall, collapse, and other accidents, may problems. Therefore, it is very important to study the physical and mechanical properties of gypsum rock.

At present, scholars at home and abroad have carried out significant research on the mechanical properties of gypsum rock. Liu et al. [2] carried out incremental loading tests of a single sample in natural and water saturated state and analyzed the creep characteristics of gypsum rock under the action of water saturated softening. Chen et al. [3] studied 
the failure mode and reliability of the lining structure of gypsum surrounding a rock tunnel. Xia et al. [4] established the cusp catastrophe model of the top protection layer of gypsum mine goaf under the effect of relative humidity and studied the instability mechanism of the top protection layer under the effect of relative humidity. Auvray et al. $[5,6]$ believed that water molecules in the atmosphere were the main reason for the change of physical and mechanical parameters of gypsum rock with time and that the relative humidity in the atmosphere strongly affected the mechanical properties of gypsum rock. Liang et al. [7] and Gao et al. [8] found that as the temperature increases, the salt solution concentration increases, the soaking time prolongs, and the mechanical strength of gypsum rocks weakens. Deng et al. [9] thought that the water content of gypsum breccia in the Taihang Mountain tunnel changed from $4 \%$ to $12 \%$, and the loss of its elastic modulus reached 99\%. Yu et al. [10] found that the changes in the microstructure of gypsum crystals in different concentrations of salt solution seriously affected its physical and mechanical properties, especially permeability, extreme strength, and deformation characteristics. Evju et al. [11] studied the growth and expansion of anhydrite in solution and found that the expansion curve of anhydrite showed a logarithmic trend. Huang et al. [12] conducted conventional triaxial compression test on anhydrite rock and believed that with the increase of confining pressure, the deformation characteristics of anhydrite changed from brittleness to ductility, the peak value and residual strength had a good linear relationship with confining pressure, and the sensitivity of residual strength to confining pressure was significantly higher than that of peak strength. Yu et al. [13] carried out triaxial compression test on natural gypsum rock, it is believed that gypsum rock has good plastic flow characteristics under different confining pressure, and there is no obvious shear failure surface after loading, but an obvious lateral expansion appears. Su et al. [14] obtained the obvious weakening effect of high-temperature dehydration on gypsum rock through the experimental study on the physical and mechanical effects of high-temperature dehydration gypsum rock. Shi et al. [15] considered the factors such as cement, gypsum, quartz sand, and barite powder, analyzed the sensitivity of these factors to similar material performance parameters by range analysis method, and obtained the quantitative relationship between uniaxial compressive strength and various influencing factors by regression analysis. Cao et al. [16] investigated the compressive strength behavior and acoustic emission (AE) characteristics of 180-day cured CTB samples by using four different loading rates: $50 \mathrm{~N} / \mathrm{s}, 100 \mathrm{~N} / \mathrm{s}, 150 \mathrm{~N} / \mathrm{s}$, and $200 \mathrm{~N} / \mathrm{s}$. Jiang et al. $[17,18]$ conducted uniaxial compression and Brazilian splitting softening tests on the argillaceous anhydrite interlayer under different soaking times and believed that its mechanical strength was negatively related to the soaking time. Cao et al. [19] studied the mechanical strength and AE properties of RCTMC; compression testing was carried out using a triaxial compression test system and $\mathrm{AE}$ monitoring system (PCI-2). Li et al. [20] performed uniaxial compression tests on gypsum rock after different times of wet and dry cycles; the results showed that the water absorption, porosity, uniaxial compressive strength, and elastic modulus were logarithmic functions with the times of dry wet cycles. Wu et al. [21] carried out an optimization study on the thickness of the buffer layer of the gypsum rock tunnel lining based on the swelling constitutive model. Zhou et al. [22] conducted uniaxial and triaxial compression tests under natural and water saturated conditions for fresh gypsum rocks retained as pillars in Jinghua gypsum mine in Jingmen city in both natural and saturated states, combined with microscopic scanning electron microscope tests to study the strength of gypsum rocks and deformation softening characteristics and mechanisms. Chiara et al. [23] proposed a relationship between electrical resistivity and saturation degree of gypsum, and the reliability of laboratory measurements is finally verified in comparison with field and modelled resistivity data. Mohammadhossein and Stanley $[24,25]$ suggest that a higher drying temperature of $80^{\circ} \mathrm{C}$ can be used for drying gypsum without transforming gypsum to hemihydrate and investigated the strength of gypsum in an as-received saturated condition using uniaxial compressive strength (UCS), Brazilian tensile strength (BTS), and point load index (PLI) tests.

Although many scholars have carried out a series of research and discussion on the physical and mechanical properties of gypsum rock, the use of A-class $\alpha$-highstrength gypsum powder to pour remolded samples, and four groups of natural, $45^{\circ} \mathrm{C}$ dehydrated, water saturated, and $220^{\circ} \mathrm{C}$ high-temperature dehydrated samples were processed in the laboratory. The ultrasonic testing, uniaxial compression, conventional triaxial compression, Brazilian splitting, X-ray diffraction, and scanning electron microscopy experiments were performed on each group of samples. The research results can provide a reference for the stability of surrounding rocks of similar materials.

\section{Materials and Methods}

2.1. Sample Preparation. In this study, A-grade $\alpha$-highstrength gypsum powder produced by Sichuan Hongtai Company was selected, which has the advantages of low water demand, high strength, high hardness, good operability, and wide application range. The remolded sample is prepared and poured according to a mass ratio of distilled water to gypsum powder of $3: 10$. After pouring, the initial setting time is 8 mins, final setting occurs 30 mins later, and the free water is lost after drying or exposure at $45^{\circ} \mathrm{C}$. The specific production process is as follows:

(1) Mold installation: adopt a plastic mold with a side length of $200 \mathrm{~mm}$, apply lubricant to the inside of the mold to facilitate mold removal, and apply Vaseline at the joint to prevent slurry loss; the pouring mold is shown in Figure 1(a).

(2) Weighing and mixing: pour a certain amount of distilled water into a 40 -litre plastic bucket, pour the weighed gypsum powder evenly into the water, stir the distilled water quickly at the same time, and fully mix it for 60 90 seconds, shaking the bucket while stirring to reduce bubbles. 


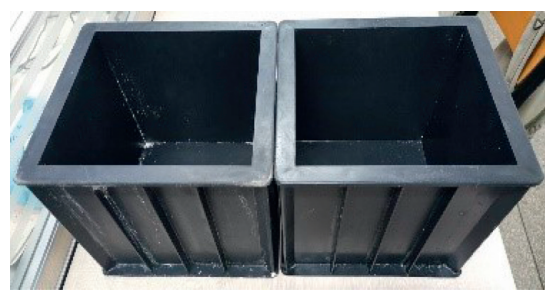

(a)

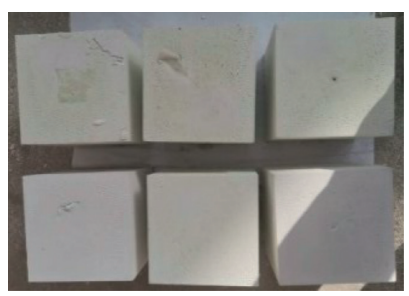

(b)

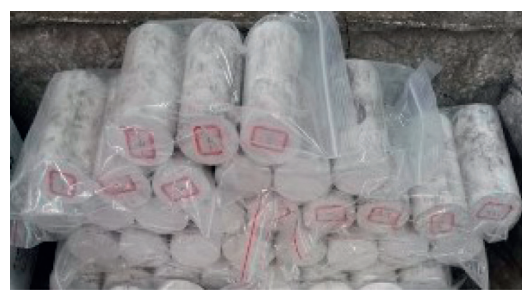

(c)

FIGURE 1: Remodeled samples of high-strength gypsum powder. (a) Casting mold. (b) Cube samples. (c) Standard samples.

(3) Production: place the mold on the vibration table, pour the stirred gypsum slurry into the mold, and then stop the shaking table after 2 mins.

(4) Demolding: when the slurry is completely solidified, cover the surface of the model with fresh-keeping film, and let it react fully. The mold can be demolded after 2 hours. The cube sample after demolding is shown in Figure 1(b).

(5) Preparation of standard sample: after the demolded sample is placed for 24 hours, it is processed into a standard cylindrical sample of $\phi 50 \times 100 \mathrm{~mm}$ in the laboratory.

The process is cooled with tap water, and the processing accuracy meets the laboratory test requirements [26]. When the processing is completed, samples are sealed with plastic wrap, as shown in Figure 1(c).

The standard samples are classified and processed to prepare the samples with different water content conditions. Among them, the samples with a size of $\phi 50 \times 100 \mathrm{~mm}$ are subjected to uniaxial and triaxial compression tests, and the samples with a size of $\phi 50 \times 25 \mathrm{~mm}$ are subjected to the Brazilian split test, as follows:

(1) Natural sample (group A): the processed standard cylindrical sample is the natural sample, which is sealed with plastic wrap. The sizes of the samples are $\phi 50 \times 100 \mathrm{~mm}\left(\mathrm{~A}_{1}-\mathrm{A}_{8}\right)$ and $\phi 50 \times 25 \mathrm{~mm}\left(\mathrm{~A}_{9}-\mathrm{A}_{11}\right)$.

(2) $45^{\circ} \mathrm{C}$ dehydrated sample (group $B$ ): put the processed standard cylindrical sample into an oven at $45^{\circ} \mathrm{C}$ and keep it for 48 hours. When the weight difference between two adjacent samples is less than $0.5 \mathrm{~g}, 45^{\circ} \mathrm{C}$ dehydrated sample is obtained and it is sealed with fresh-keeping film. The sizes of the samples are $\phi 50 \times 100 \mathrm{~mm}\left(\mathrm{~B}_{1}-\mathrm{B}_{8}\right)$.

(3) Water saturated sample (group C): place the processed standard cylindrical sample into a watersaturated instrument and vacuum force water saturation for 24 hours. When the mass difference between two adjacent samples is less than $0.2 \mathrm{~g}$, the water saturated sample is obtained, which is sealed with a fresh-keeping film. The sizes of the samples are $\phi 50 \times 100 \mathrm{~mm}\left(\mathrm{C}_{1}-\mathrm{C}_{8}\right)$ and $\phi 50 \times 25 \mathrm{~mm}\left(\mathrm{C}_{9}-\mathrm{C}_{11}\right)$.

(4) High-temperature dehydrated sample (group D): put the processed standard cylindrical sample into a KSW-5D-12 high-temperature box resistance furnace with an electric furnace temperature controller, heat it to $220^{\circ} \mathrm{C}$ at the rate of $10^{\circ} \mathrm{C} / \mathrm{min}$, weigh it at a certain time interval. If, after 15 hours, the difference between two weighing is not more than $0.2 \mathrm{~g}$, it is considered that the crystal water inside the sample is completely dehydrated, and it is sealed with plastic wrap. The sizes of the samples are $\phi 50 \times 100 \mathrm{~mm}$ $\left(\mathrm{D}_{1}-\mathrm{D}_{8}\right)$ and $\phi 50 \times 25 \mathrm{~mm}\left(\mathrm{D}_{9}-\mathrm{D}_{11}\right)$.

\subsection{Testing Device}

2.2.1. Ultrasound Testing Device. The rock wave velocity is one of the important parameters that reflect rock joint cracks and compactness; $50 \mathrm{~Hz}$ common sensor is used, as shown in Figure 2. First, connect the transmitter and receiver and measure the system lag time $t_{0}$ caused by the thickness of instrument; then the sample is placed between the transmitter and receiver, which are applied Vaseline cream on the section of sensors and sample; measure the travel time $t$ of the sound wave, and calculate the wave velocity $v_{p}$ of the rock ultrasonic wave according to the following formula:

$$
v_{p}=\frac{L}{\Delta t},
$$

where $v_{p}$ is longitudinal wave velocity, $\mathrm{m} / \mathrm{s} ; L$ is sample length, $m$; and $\Delta t$ is wave's travel time, $\Delta t=t-t_{0}$.

2.2.2. Mechanical Testing Device. The test was performed on the RMT-150B electrohydraulic servo rock test system [27], as shown in Figure 3. The axial load is measured with a $1000 \mathrm{kN}$ force sensor with a load accuracy of $1.0 \times 10^{-3} \mathrm{kN}$, the axial compression deformation is measured with a $5.0 \mathrm{~mm}$ displacement sensor, and the circumferential deformation is measured by two $2.5 \mathrm{~mm}$ displacement sensors with a deformation accuracy of $1.0 \times 10^{-3} \mathrm{~mm}$. The maximum confining pressure is $50 \mathrm{MPa}$. It can carry out tests such as rock uniaxial compression, indirect (direct) stretching, and compression-shear and triaxial compression tests. It can adopt various control modes of load, displacement, and stroke. During the test, the computer automatically collects the load and deformation and displays them in real time.

\subsection{Test Methods}

(1) Measurement of sample size, mass, and longitudinal wave velocity: the sample size is measured by a 


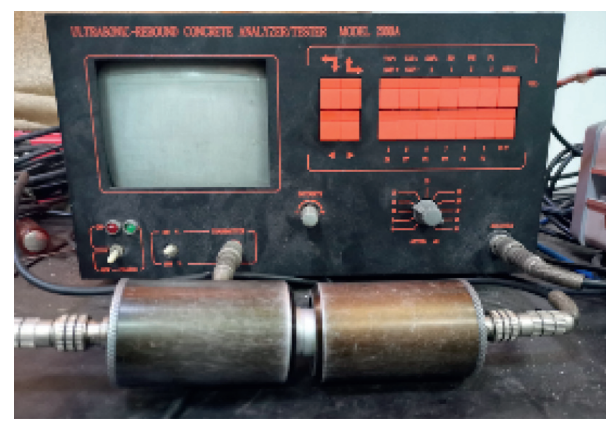

FIgURE 2: UTA2001A ultrasonic inspection monitor.

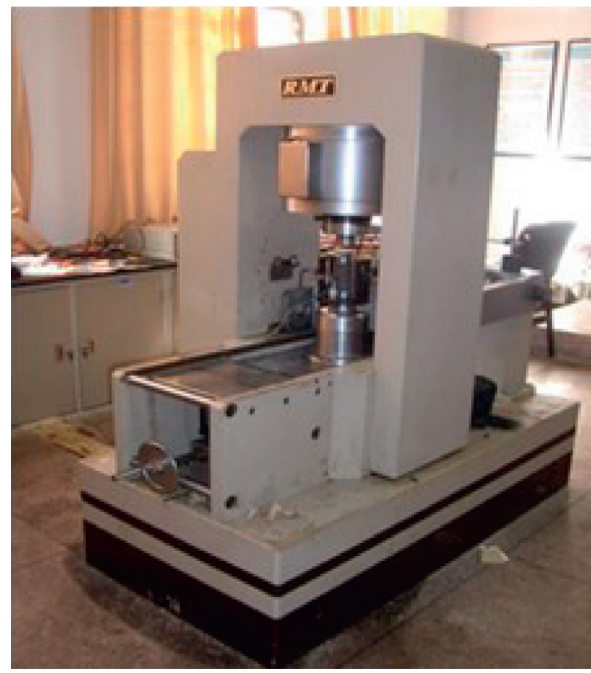

(a)

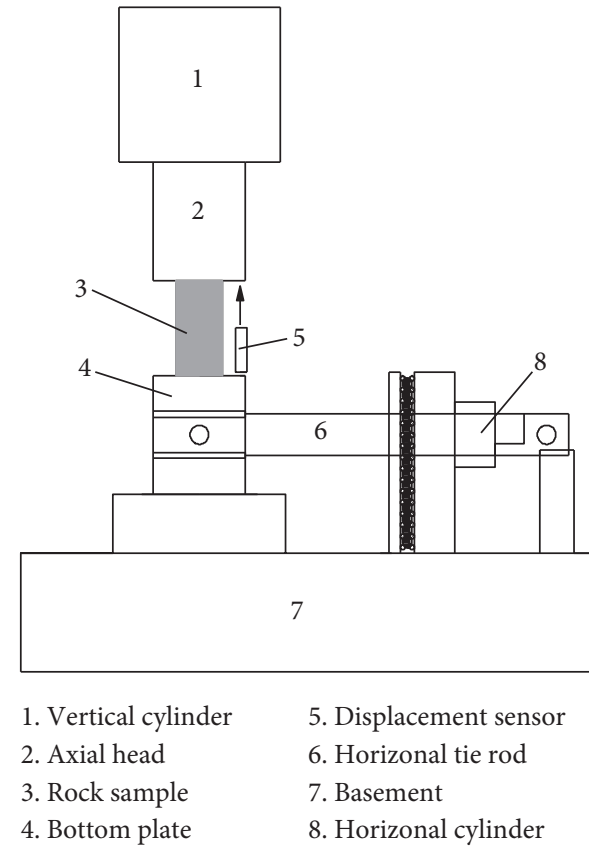

(b)

FIgURE 3: Electrohydraulic servo rock test system of RMT-150B. (a) Test system. (b) Schematic diagram of uniaxial compression.

Vernier caliper, and the mass is weighed by an electronic scale. The UTA-2000A intelligent ultrasonic monitor is used for the longitudinal wave velocity (as shown in Figure 2). The sampling frequency is $10 \mathrm{MHz}$; sensor frequency is $35 \mathrm{kHz}$, accuracy is $0.1 \mu \mathrm{s}$, and Vaseline cream as coupling agent is used between the sample and sensors.

(2) Uniaxial compression and Brazilian split tests: the test was performed on the RMT-150B electrohydraulic servo test system, as shown in Figure 3. The axial compression deformation is measured with a $5 \mathrm{~mm}$ displacement sensor, and the axial load is measured with a $1000 \mathrm{kN}$ force sensor. The displacement control mode is adopted in the test, and the loading rate is $0.005 \mathrm{~mm} / \mathrm{s}$. During the test, the load and deformation are automatically collected and displayed in real time. The test system can obtain the whole stress-strain curve during the uniaxial compression of the sample, as shown in Figures 4(a) and $4(\mathrm{~b})$.

(3) Triaxial compression test: the test equipment is the same as in (2). First, the axial pressure and confining pressure are loaded to the state of hydrostatic pressure $(3,6,9,12$, and $15 \mathrm{MPa})$ using the force control, and then constant confining pressure is kept. The axial pressure force control is changed to displacement control (at a loading rate of $0.005 \mathrm{~mm} / \mathrm{s}$ ) to apply axial pressure to the sample for damage, as shown in Figure 4(c).

(4) Sample composition analysis: after the test, the sample fragments were microscopically analyzed by D8-ADVNCE X-ray diffraction composition and JSM-6390LV electron microscopy (SEM). All the work was completed in the cultivation base of the National Key Laboratory jointly established by Henan Province. 


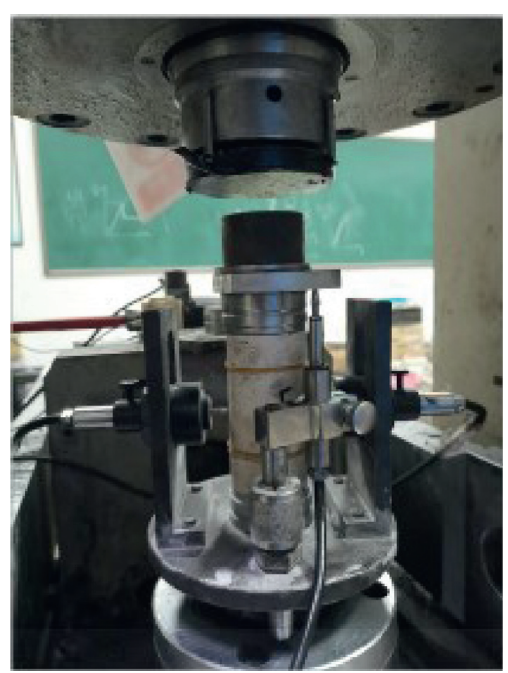

(a)

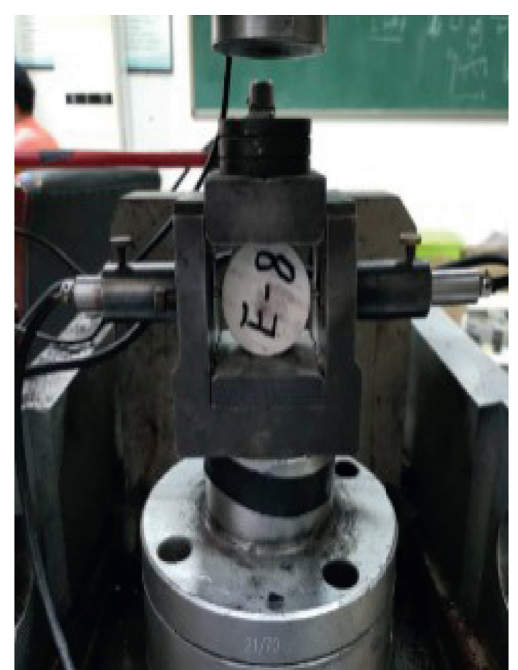

(b)

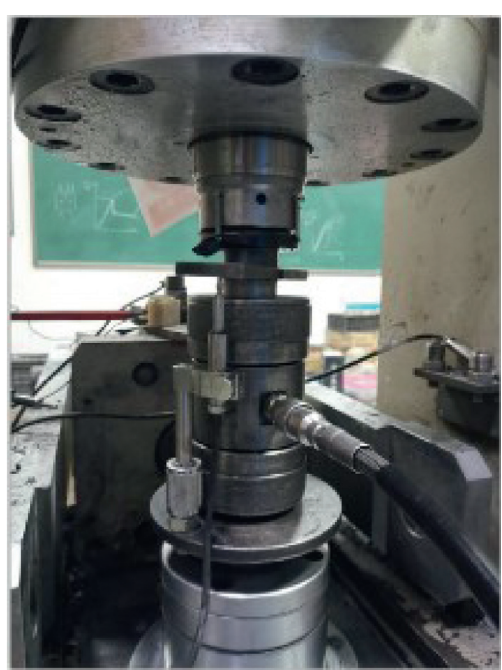

(c)

Figure 4: Test of physical and mechanical properties of the high-strength gypsum powder remolded sample. (a) Uniaxial compression. (b) Brazil spilt. (c) Triaxial compression.

\section{Test Results and Analysis}

3.1. Ultrasonic Test Results. The size and quality of samples in different states were tested, and the density of each group of samples is shown in Figure 5(a). It can be observed that the apparent density of eight natural (group A) samples is $1.87 \sim 1.95 \mathrm{~g} / \mathrm{cm}^{3}$, with an average of $1.91 \mathrm{~g} / \mathrm{cm}^{3}$. After heating at $45^{\circ} \mathrm{C}$ for $48 \mathrm{~h}$, the average loss of free water of eight group B samples is $22.33 \mathrm{~g}$, the apparent density is $1.78 \sim 1.83 \mathrm{~g} / \mathrm{cm}^{3}$, with an average of $1.80 \mathrm{~g} / \mathrm{cm}^{3}$, and the density decreased approximately by $0.11 \mathrm{~g} / \mathrm{cm}^{3}$. After $24 \mathrm{~h}$ of forced water saturation, the average mass of eight group $\mathrm{C}$ samples increased by $33.48 \mathrm{~g}$, the apparent density of the samples is $1.936 \sim 1.974 \mathrm{~g} / \mathrm{cm}^{3}$, with an average of $1.953 \mathrm{~g} / \mathrm{cm}^{3}$, and the density increased by about $0.043 \mathrm{~g} / \mathrm{cm}^{3}$. After $12 \mathrm{~h}$ of high temperature at $220^{\circ} \mathrm{C}$, the average loss of free water of eight group D samples is $97.15 \mathrm{~g}$, the apparent density of the samples is $1.395 \sim 1.421 \mathrm{~g} / \mathrm{cm}^{3}$, with an average of $1.412 \mathrm{~g} /$ $\mathrm{cm}^{3}$, and the density reduced by $0.498 \mathrm{~g} / \mathrm{cm}^{3}$.

The longitudinal wave velocity of samples in different states was tested, and the longitudinal wave velocity of each group of samples is shown in Figure 5(b). It can be observed that the wave velocity of eight natural (group A) samples is $2973 \sim 3140 \mathrm{~m} / \mathrm{s}$, with an average value of $3093 \mathrm{~m} / \mathrm{s}$. After heating at $45^{\circ} \mathrm{C}$ for $48 \mathrm{~h}$, the wave velocity of eight group B samples is $2973 \sim 3140 \mathrm{~m} / \mathrm{s}$, with an average value of $2967 \mathrm{~m} / \mathrm{s}$ and with a decrease of $4.07 \%$. After forced water saturation for 24 hours, the wave velocity of 8 group $\mathrm{C}$ samples is $2975 \sim 3086 \mathrm{~m} / \mathrm{s}$, with an average value of $3017 \mathrm{~m} / \mathrm{s}$ and with a decrease of $2.46 \%$. After heating at $220^{\circ} \mathrm{C}$ for $12 \mathrm{~h}$, the wave velocity of eight group D samples is $1200-1892 \mathrm{~m} / \mathrm{s}$, with an average value of $1200 \sim 1892 \mathrm{~m} / \mathrm{s}$ and with an average value of $1531 \mathrm{~m} / \mathrm{s}$, which was reduced by approximately $50.5 \%$.

The above analysis shows that the density of the water saturated sample and the longitudinal wave velocity of the natural sample are the highest. Due to the loss of water in the crystal structure in a high-temperature environment, the internal structure of the sample is damaged, resulting in the lowest density and wave velocity of the high-temperature dehydration sample. Compared with the natural sample, the density and wave velocity of the high-temperature sample decreased by $26.07 \%$ and $50.5 \%$, respectively. This may be due to the uneven heating of the minerals inside the sample, which causes incongruous deformation and expansion and then generates micromechanical cracks. At the same time, the crystal is cracked after heating, which causes the corresponding physical and mechanical changes in the sample's internal structural conditions and material properties, and the sample will have cracks and defects with complex distribution. When ultrasonic waves encounter cracks and defects during propagation, they undergo refraction, diffraction, and other phenomena. The decrease in the waveguide property and the increase in energy attenuation will lead to the decrease in $P$ wave velocity. The $P$ wave velocity is closely related to the mechanical properties of the sample after high-temperature dehydration, and it can indirectly reflect the mechanical deterioration characteristics of the sample after high-temperature dehydration.

\subsection{Deformation and Strength Characteristics}

3.2.1. Uniaxial Compression. Figure 6 shows the complete stress-strain curve of each group of samples under different states in the uniaxial compression test. Table 1 lists the test results of each group of samples. In the table, $\sigma_{1}$ is the peak strength, $E_{T}$ is the static elastic modulus (taking the slope of the peak strength of $30 \% \sim 70 \%$ approximate to the linear section) [28,29], and $E_{50}$ is the deformation modulus (taking the slope of the $50 \%$ peak strength point of the axial stressstrain curve to the origin).

In Figure 6, it can be observed that the stress-strain curve of each group of specimens under different states has experienced four stages, namely, compaction, elasticity, yield, 


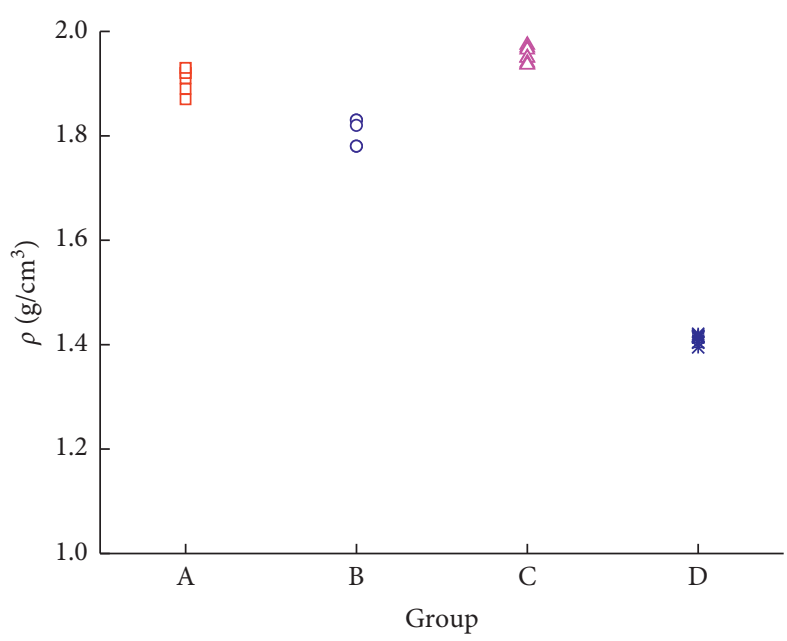

(a)

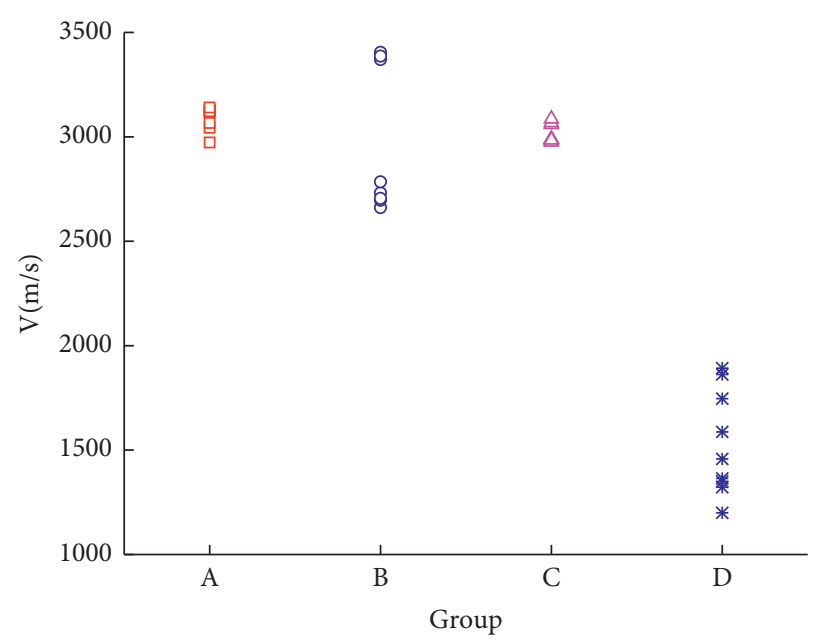

(b)

FIGURE 5: Density and longitudinal wave velocity of each group of samples. (a) Density. (b) Longitudinal wave velocity.

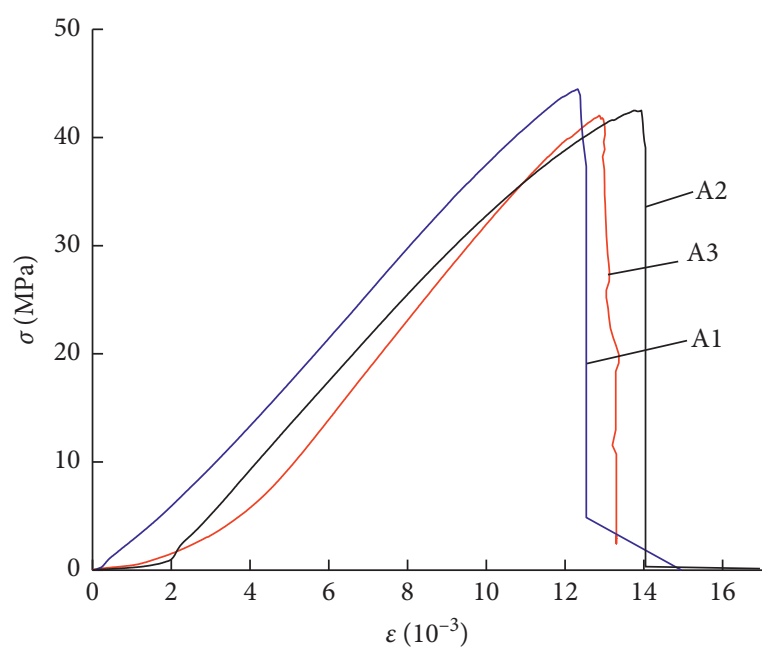

(a)

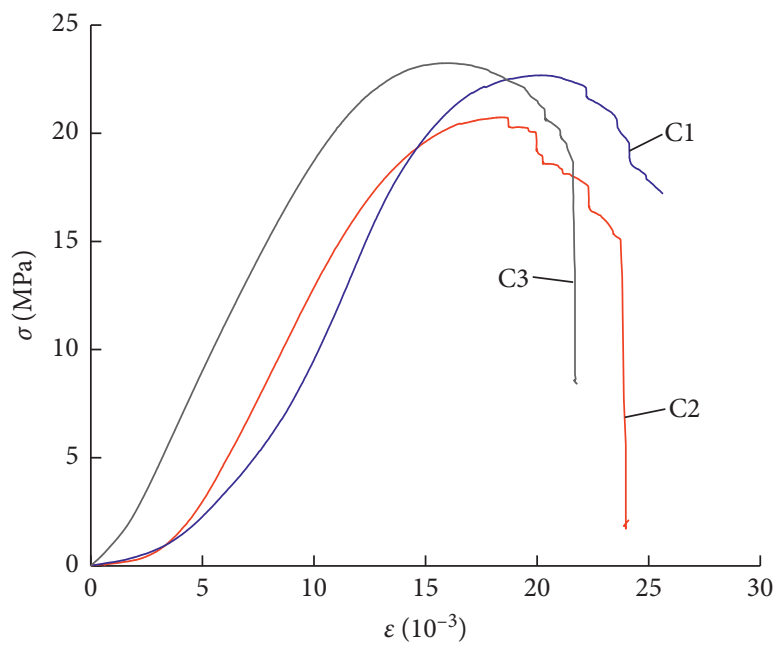

(c)

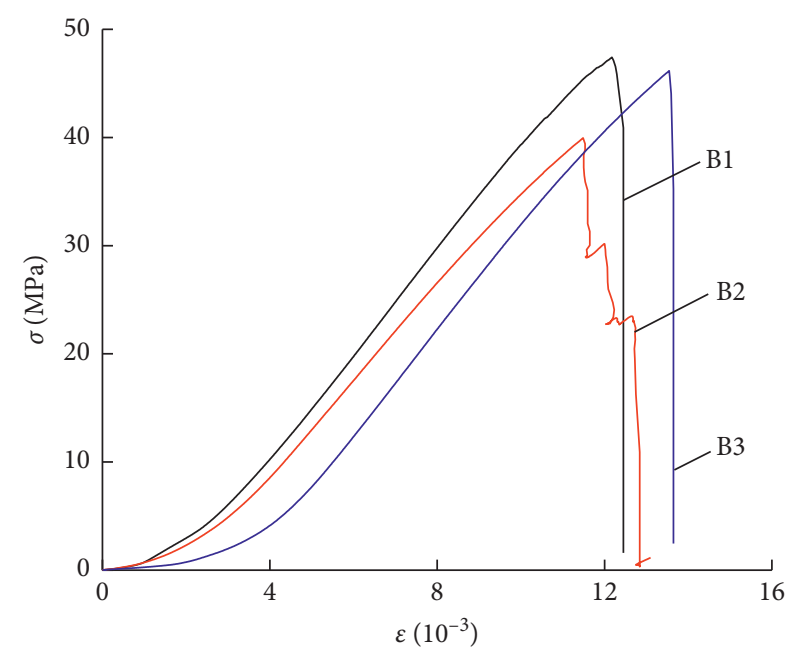

(b)

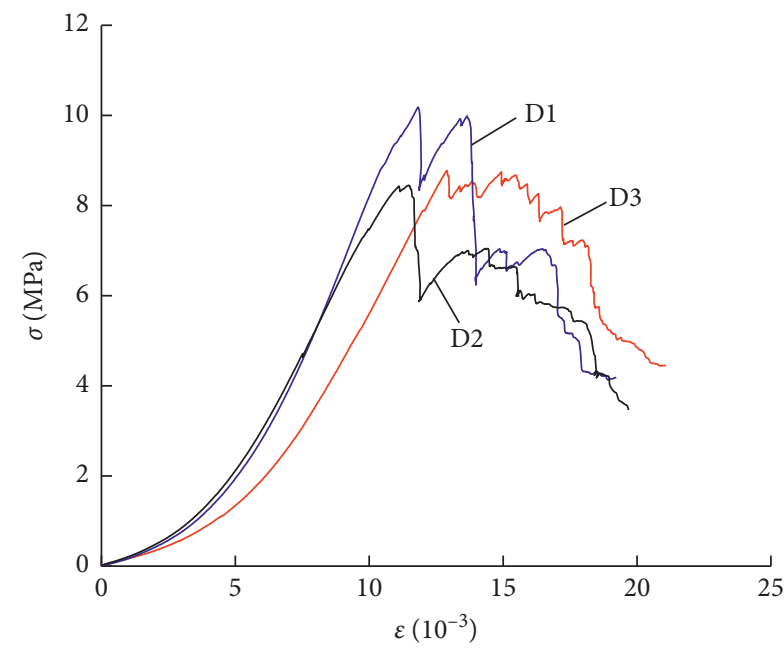

(d)

Figure 6: Stress-strain curve of each group of samples during uniaxial compression test. (a) Natural. (b) Dehydration at $45^{\circ} \mathrm{C}$. (c) Water saturation. (d) High-temperature dehydration at $220^{\circ} \mathrm{C}$. 
TABLE 1: Uniaxial compression test results of high-strength gypsum powder remolded samples.

\begin{tabular}{|c|c|c|c|c|}
\hline & No. & $\sigma_{1}(\mathrm{MPa})$ & $E_{T}(\mathrm{GPa})$ & $E_{50}(\mathrm{GPa})$ \\
\hline \multirow{4}{*}{ Natural } & $\mathrm{A}_{1}$ & 44.53 & 4.11 & 3.59 \\
\hline & $\mathrm{A}_{2}$ & 42.53 & 3.96 & 3.07 \\
\hline & $\mathrm{A}_{3}$ & 32.84 & 3.55 & 2.18 \\
\hline & Average & 39.96 & 3.87 & 2.95 \\
\hline \multirow{5}{*}{ Water saturation } & $\mathrm{C}_{1}$ & 22.64 & 2.19 & 1.05 \\
\hline & $\mathrm{C}_{2}$ & 20.75 & 2.02 & 1.18 \\
\hline & $\mathrm{C}_{3}$ & 23.21 & 2.07 & 1.87 \\
\hline & Average & 22.20 & 2.09 & 1.36 \\
\hline & No. & $\sigma_{\mathrm{c}}(\mathrm{MPa})$ & $E_{T}(\mathrm{GPa})$ & $E_{50}(\mathrm{GPa})$ \\
\hline \multirow{4}{*}{$45^{\circ} \mathrm{C}$ dehydration } & $\mathrm{B}_{1}$ & 47.42 & 4.96 & 3.49 \\
\hline & $\mathrm{B}_{2}$ & 40.02 & 4.51 & 3.06 \\
\hline & $\mathrm{B}_{3}$ & 46.17 & 4.91 & 2.83 \\
\hline & Average & 44.53 & 4.79 & 3.13 \\
\hline \multirow{4}{*}{$220^{\circ} \mathrm{C}$ high-temperature dehydration } & $\mathrm{D}_{1}$ & 10.18 & 1.34 & 0.64 \\
\hline & $\mathrm{D}_{2}$ & 8.47 & 1.11 & 0.60 \\
\hline & $\mathrm{D}_{3}$ & 8.78 & 1.00 & 0.50 \\
\hline & Average & 9.14 & 1.15 & 0.58 \\
\hline
\end{tabular}

and failure. (1) Compaction stage: the original pores and cracks in the sample are slowly compacted, forming nonlinear compression deformation and concave shape on the stress-strain curve. (2) Elastic stage: the stressstrain curve shows a linear relationship, obeys Hooke's law, and shows the elastic characteristics of the specimen. (3) Yield stage: as the axial stress continues to load, the material with a lower strength inside the specimen first enters the yield failure stage, the stress-strain curve deviates from the straight line, and the rate of increase in axial stress gradually decreases. (4) Destruction stage: when the specimen reaches the ultimate strength, a macroscopic slip occurs inside the specimen along a fracture surface. At the initial stage of slip, due to the friction, the specimen undergoes tensile stress in the longitudinal direction. The bearing capacity of the sample decreases rapidly as the deformation increases, and the deformation of the sample changes at an increasing rate, which further exacerbates the deformation damage of the sample. Among them, the natural samples, dehydrated samples at $45^{\circ} \mathrm{C}$, and water saturated samples show good linear characteristics before the peak value, with an obvious peak point; after the peak value, the stress drops rapidly, showing the typical brittle failure. However, the high-temperature dehydrated samples show multiple peaks after the peak; the curve twists and turns obviously, and the postpeak shows plastic failure characteristics.

As can be seen from Table 1, the deformation parameters of the high-strength gypsum powder remolded sample are closely related to the internal water content of the sample. The peak strength of the sample dehydrated at $45^{\circ} \mathrm{C}$ is approximately $31.12 \%$ higher than that of the natural sample, whereas the peak strength of the sample after water saturation is reduced by approximately $34.63 \%$. Water saturation has a weakening effect on the high-strength gypsum remolded sample. After high-temperature dehydration, the strength of the sample decreased by $73.09 \%$. It can be observed that high-temperature dehydration has obvious weakening effect on the sample.

3.2.2. Triaxial Compression. Figure 7 shows the complete stress-strain curve of each group of samples under different states in the triaxial compression test. Table 2 lists the test results of each group of samples. In the table, $\sigma_{1}$ is the peak strength, $E_{T}$ is the static elastic modulus (taking the slope of the peak strength of $30 \% \sim 70 \%$ approximate to the linear section), $E_{50}$ is the deformation modulus (taking the slope of the $50 \%$ peak strength point of the axial stress-strain curve to the origin), $c$ is cohesion ( $\mathrm{MPa})$, and $\varphi$ is internal friction angle $\left({ }^{\circ}\right)$.

As can be seen form Table 2, the peak strength of the specimen gradually increases with the increase of confining pressure, whereas the change in confining pressure has little effect on the elastic modulus and deformation modulus of the specimen. The relationship between the peak strength and confining pressure is linear, which is in accordance with the Coulomb strength criterion.

According to the Coulomb strength criterion, the maximum shear stress of the specimen is determined using cohesion and internal friction angle, which can be expressed as follows:

$$
\tau=c+\mu \sigma
$$

where $c$ is cohesion (MPa), $\mu$ is internal friction coefficient, $\mu=\tan \varphi, \varphi$ is the internal friction angle $\left(^{\circ}\right)$, and $\sigma$ is the normal stress on the failure surface $(\mathrm{MPa})$. If expressed as principal stress, then

$$
\sigma_{1}=k \sigma_{3}+Q
$$

In the formula, $\sigma_{1}$ is the peak strength $(\mathrm{MPa}), k$ and $Q$ are the material strength parameters, and the relationship between the value, the internal friction angle $\varphi$, and the cohesion $c$ is 


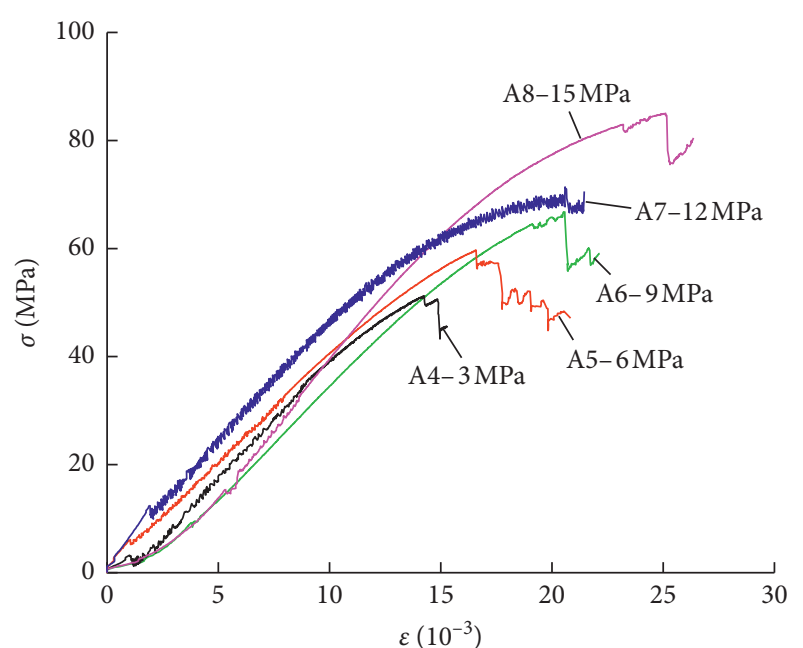

(a)

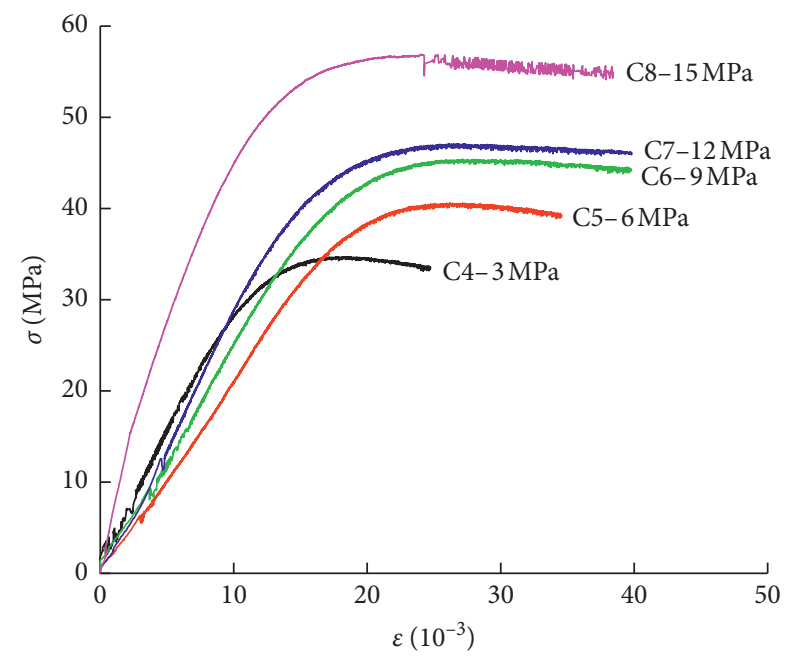

(c)

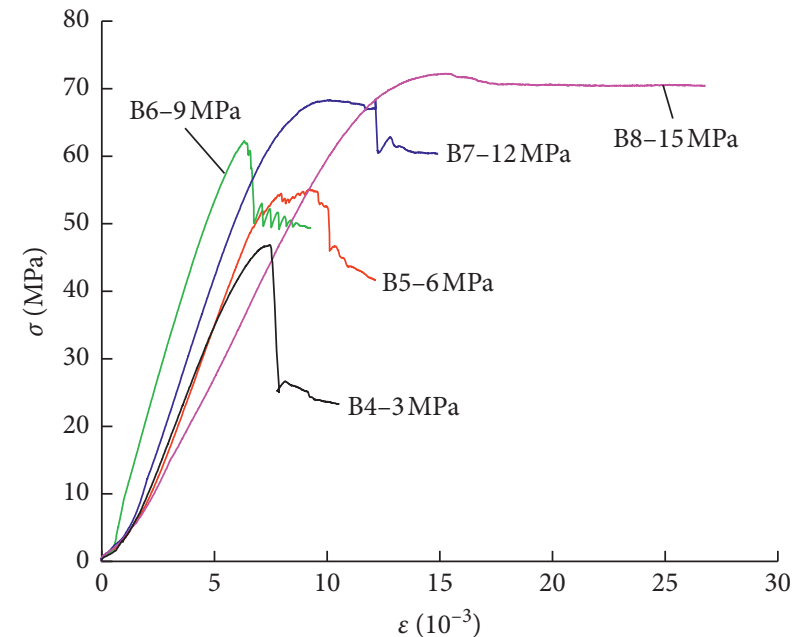

(b)

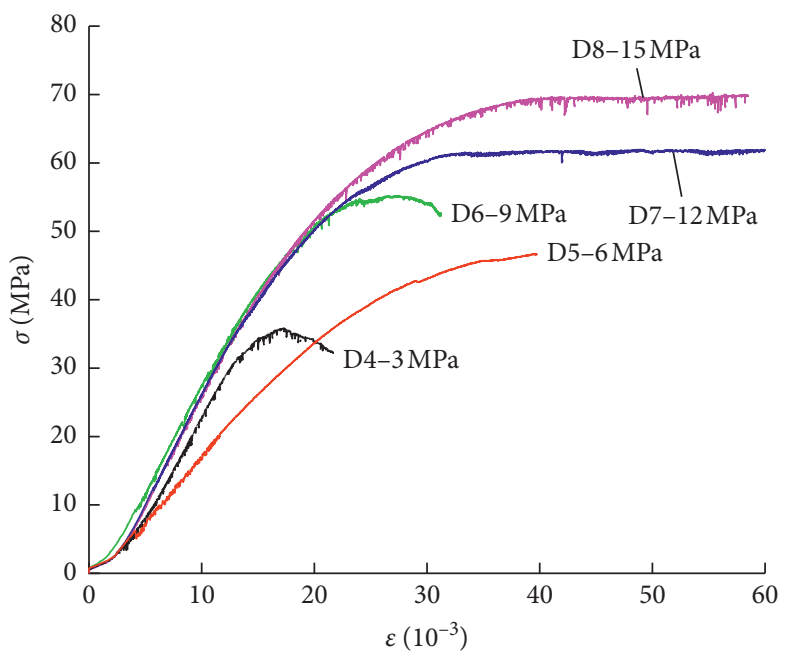

(d)

Figure 7: Complete stress-strain curve of each group of samples during triaxial compression test. (a) Natural. (b) Dehydration at $45^{\circ} \mathrm{C}$. (c) Water saturation. (d) High-temperature dehydration at $220^{\circ} \mathrm{C}$.

TABLE 2: Triaxial compression test results of high-strength gypsum powder remolded samples.

\begin{tabular}{|c|c|c|c|c|c|c|c|}
\hline & No. & $\sigma_{3}(\mathrm{MPa})$ & $\sigma_{1}(\mathrm{MPa})$ & $E_{T}(\mathrm{GPa})$ & $E_{50}(\mathrm{GPa})$ & $c(\mathrm{MPa})$ & $\varphi\left(^{\circ}\right)$ \\
\hline \multirow{5}{*}{ Natural } & $\mathrm{A}_{4}$ & 3 & 51.16 & 4.54 & 3.77 & \multirow{5}{*}{13.18} & \multirow{5}{*}{27} \\
\hline & $\mathrm{A}_{5}$ & 6 & 59.79 & 3.98 & 3.82 & & \\
\hline & $\mathrm{A}_{6}$ & 9 & 66.80 & 4.03 & 4.07 & & \\
\hline & $\mathrm{A}_{7}$ & 12 & 71.49 & 3.96 & 4.09 & & \\
\hline & $\mathrm{A}_{8}$ & 15 & 85.13 & 4.54 & 5.06 & & \\
\hline \multirow{5}{*}{ Water saturation } & $\mathrm{C}_{4}$ & 3 & 34.71 & 2.79 & 2.66 & \multirow{5}{*}{11.39} & \multirow{5}{*}{15} \\
\hline & $\mathrm{C}_{5}$ & 6 & 40.68 & 2.25 & 2.11 & & \\
\hline & $\mathrm{C}_{6}$ & 9 & 45.33 & 2.37 & 2.45 & & \\
\hline & $\mathrm{C}_{7}$ & 12 & 47.00 & 2.62 & 2.93 & & \\
\hline & $\mathrm{C}_{8}$ & 15 & 56.98 & 3.49 & 4.18 & & \\
\hline \multirow{5}{*}{$45^{\circ} \mathrm{C}$ dehydration } & $\mathrm{B}_{4}$ & 3 & 46.75 & 8.50 & 7.56 & \multirow{5}{*}{14.25} & \multirow{5}{*}{21.3} \\
\hline & $\mathrm{B}_{5}$ & 6 & 55.07 & 9.24 & 8.14 & & \\
\hline & $\mathrm{B}_{6}$ & 9 & 62.29 & 11.02 & 11.68 & & \\
\hline & $\mathrm{B}_{7}$ & 12 & 66.58 & 9.62 & 10.10 & & \\
\hline & $\mathrm{B}_{8}$ & 15 & 72.09 & 6.61 & 6.55 & & \\
\hline \multirow{5}{*}{$220^{\circ} \mathrm{C}$ high-temperature dehydration } & $\mathrm{D}_{4}$ & 3 & 35.86 & 2.86 & 2.46 & \multirow{5}{*}{8.50} & \multirow{5}{*}{28.7} \\
\hline & $\mathrm{D}_{5}$ & 6 & 46.72 & 1.65 & 1.82 & & \\
\hline & $\mathrm{D}_{6}$ & 9 & 55.23 & 2.87 & 2.90 & & \\
\hline & $\mathrm{D}_{7}$ & 12 & 63.10 & 2.43 & 2.94 & & \\
\hline & $\mathrm{D}_{8}$ & 15 & 70.29 & 2.26 & 2.88 & & \\
\hline
\end{tabular}




$$
\begin{gathered}
\varphi=\frac{\arcsin (k-1)}{(k+1)}, \\
c=\frac{Q(1-\sin \varphi)}{(2 \cos \varphi)} .
\end{gathered}
$$

According to formula (3), the relationship between peak strength and confining pressure of the high-strength gypsum powder remolded sample is obtained, as presented in Table 3 and Figure 8. It can be observed that the influence coefficient of the confining pressure of gypsum rock remolded samples is approximately $1.70 \sim 2.84$, and the correlation coefficient is greater than 0.95 , indicating that the peak strength of triaxial compression of each group of samples has a good correlation with the confining pressure, which conforms to the Coulomb strength criterion. According to formulas (4) and (5), the cohesion and internal friction angle of each group of samples are obtained, as presented in Table 2 .

According to formulas (4) and (5), the cohesion $c$ and internal friction angle $\varphi$ of each group of high-strength gypsum powder remolded samples are calculated. Figure 9 shows the relationship between cohesion, internal friction angle, and water content of each group of samples. It can be observed that the internal friction angle of the natural samples decreased by $21.11 \%$ after $45^{\circ} \mathrm{C}$ dehydration and by $44.44 \%$ after water saturation, whereas the internal friction angle of the samples is increased by $6.3 \%$ after $220^{\circ} \mathrm{C}$ hightemperature dehydration. The cohesion of the natural samples increased by $8.12 \%$ after $45^{\circ} \mathrm{C}$ dehydration and decreased by $13.58 \%$ after water saturation, whereas the cohesion of the samples decreased by approximately $35.51 \%$ after $220^{\circ} \mathrm{C}$ high-temperature dehydration. According to the above analysis, the cohesion and internal friction angle of the sample are closely related to the water content. After $45^{\circ} \mathrm{C}$ dehydration, the cohesion of the sample is the largest; the internal friction angle of the saturated sample is the smallest. After $220^{\circ} \mathrm{C}$ high-temperature dehydration, the cohesion of the sample is the smallest, and the internal friction angle of the sample is the largest.

Figure 10 shows the stress-strain curve of conventional triaxial compression specimen under the same confining pressure and different water content conditions.

It can be observed in Figure 10 that the deformation characteristics of the high-strength gypsum powder remolded samples are greatly different under the same confining pressure owing to the influence of water content. Similarly, the triaxial compressive stress-strain curve of each group of samples under different water content states approximately goes through the four stages of compaction, elasticity, yield, and failure. Among them, the natural sample shows obvious brittle failure after the peak, the $45^{\circ} \mathrm{C}$ dehydrated sample shows obvious brittle failure characteristics when the confining pressure is lower than $12 \mathrm{MPa}$, and the saturated and high-temperature dehydrated samples show plastic failure after the peak value. The peak strain of the $45^{\circ} \mathrm{C}$ dehydrated sample is the smallest when it reaches the peak strength, followed by that of the natural sample, whereas that of the high-temperature dehydrated sample is
TABle 3: Tensile strength of remolded sample of high-strength gypsum power.

\begin{tabular}{lcc}
\hline No. & & $R_{t}(\mathrm{MPa})$ \\
\hline & $\mathrm{A}_{9}$ & 3.858 \\
Natural & $\mathrm{A}_{10}$ & 3.939 \\
& $\mathrm{~A}_{11}$ & 3.76 \\
& $\mathrm{C}_{9}$ & 1.452 \\
Water saturation & $\mathrm{C}_{10}$ & 1.53 \\
& $\mathrm{C}_{14}$ & 1.467 \\
$220^{\circ} \mathrm{C}$ high-temperature dehydration & $\mathrm{D}_{9}$ & 0.142 \\
& $\mathrm{D}_{10}$ & 0.262 \\
& $\mathrm{D}_{11}$ & 0.215 \\
\hline
\end{tabular}

the largest. Compared with the natural sample, the peak strength of the $45^{\circ} \mathrm{C}$ dehydrated sample, saturated sample, and high-temperature dehydrated sample decreased in varying degrees. The proportion of peak strength reduction of the saturated sample is the largest, followed by that of the high-temperature dehydrated sample, whereas that of the $45^{\circ} \mathrm{C}$ dehydrated sample is the smallest. It can be observed that both water saturation and dehydration have a weakening effect on the high-strength gypsum powder remolded sample. Water saturation has the most obvious weakening effect on the strength of the sample, followed by hightemperature dehydration, whereas $45^{\circ} \mathrm{C}$ dehydration has the least weakening effect.

This may be because after the crystal of the sample was pyrolyzed and dehydrated, the number of internal pores in the sample increases, the stiffness of the bearing structure decreases, and the compression deformation increases accordingly. After the sample is forcedly saturated with water, the number of internal pores increases, the stiffness of the bearing structure increases, and the compression deformation will decrease accordingly. During the whole compression process, elastic plastic deformation occurs, which consists of three stages: crack closure, inter particle sliding, and material elastic deformation. In the initial stage, before the peak of the natural and $45^{\circ} \mathrm{C}$ dehydrated samples, nonlinear deformation crack closure is dominant, the linear section is dominated by interparticle slip and material elastic deformation, and the nonlinear section is composed of yield and plastic deformation. After reaching the peak strength, the stress of the natural and $45^{\circ} \mathrm{C}$ dehydrated samples drops rapidly, showing the typical brittle failure. The pores formed by water molecules in the high-temperature dehydrated sample increase the macroscopic strain of the sample, which shows that the postpeak strain value is larger. The water molecules between particles in the saturated sample exist in a free state, which reduces the friction between the mineral particles, decreases the strength of the sample, and increases the strain compared with the natural and the $45^{\circ} \mathrm{C}$ dehydrated samples.

3.2.3. Brazilian Split. The calculation formula of the Brazilian disc splitting test for each group of samples under different water content states is as follows: 


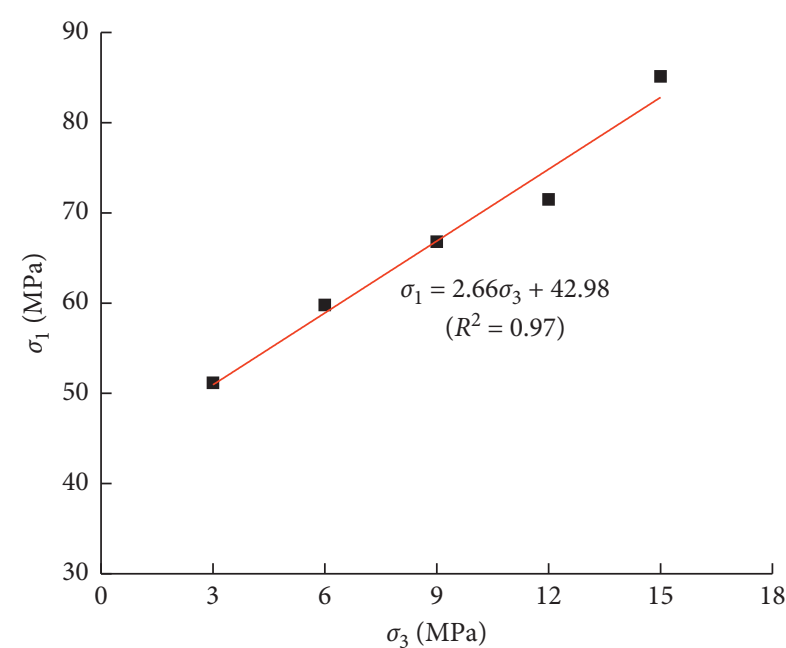

(a)

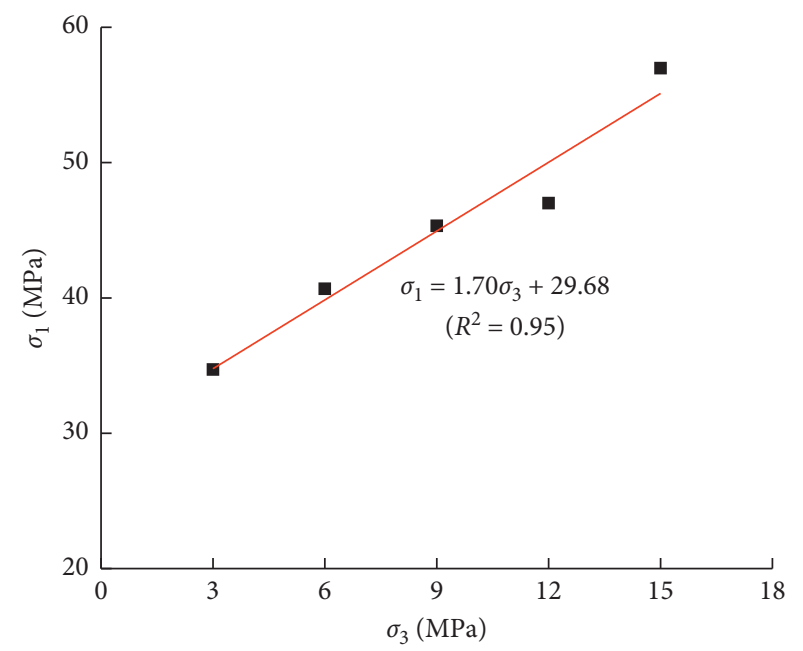

(c)

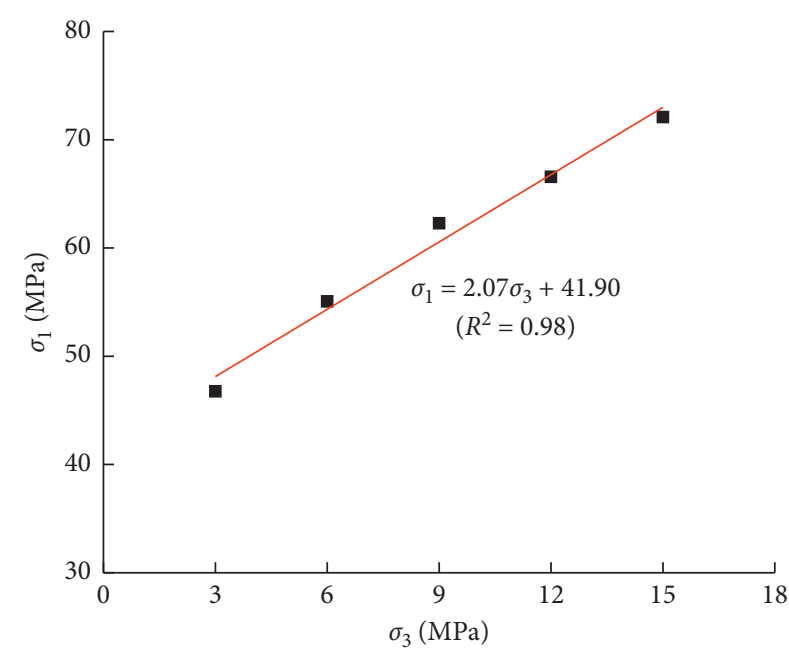

(b)

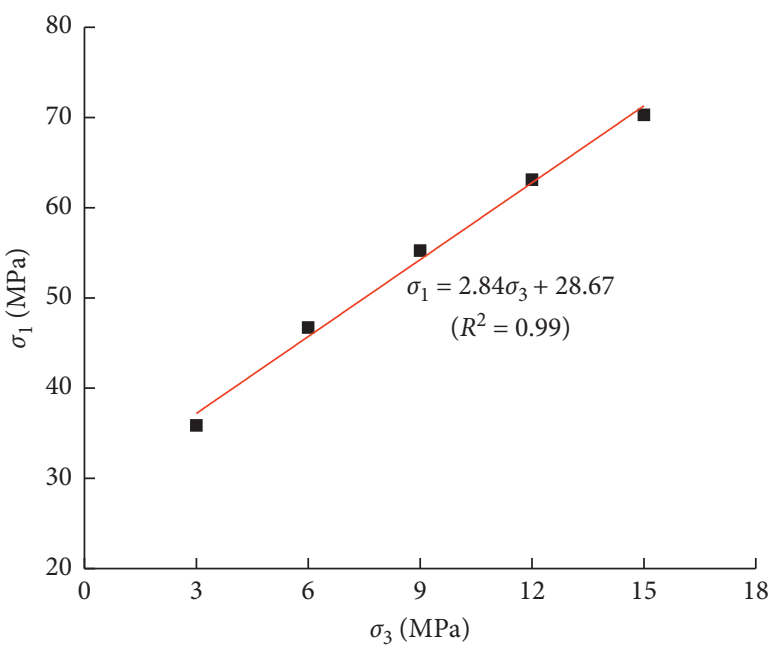

(d)

FIGURE 8: Relationship curve between peak strength and confining pressure of each group of samples under triaxial compression. (a) Natural. (b) Dehydration at $45^{\circ} \mathrm{C}$. (c) Water saturation. (d) High-temperature dehydration at $220^{\circ} \mathrm{C}$.

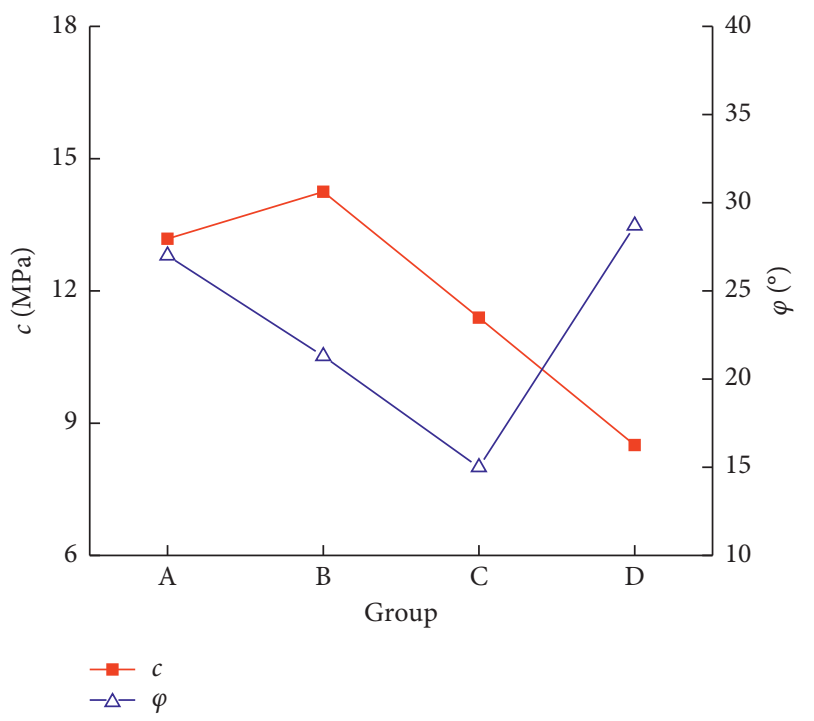

FIGURE 9: Relationship between cohesion, internal friction angle, and water content of each group of samples. 


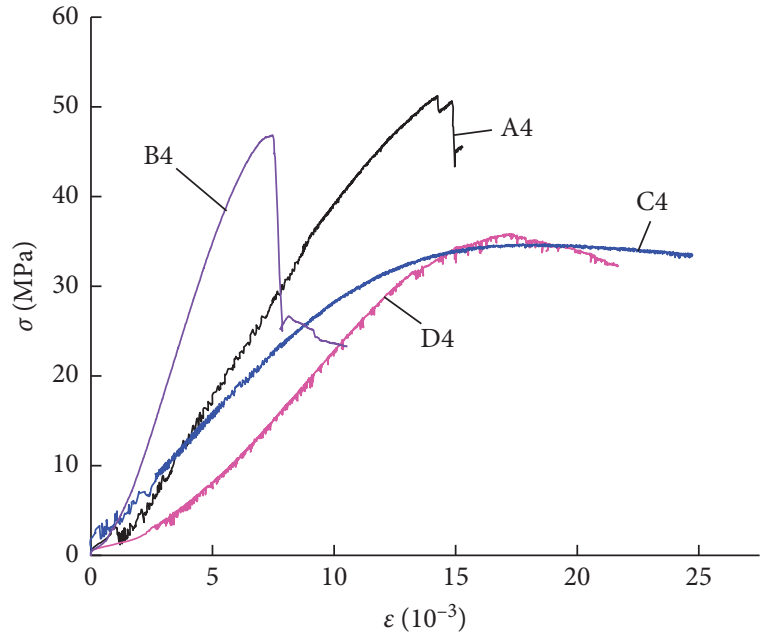

(a)

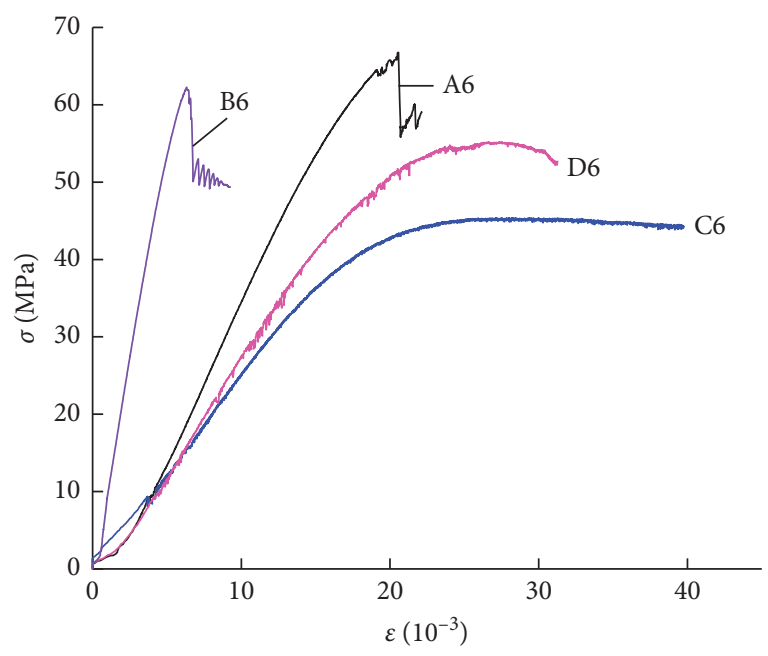

(c)

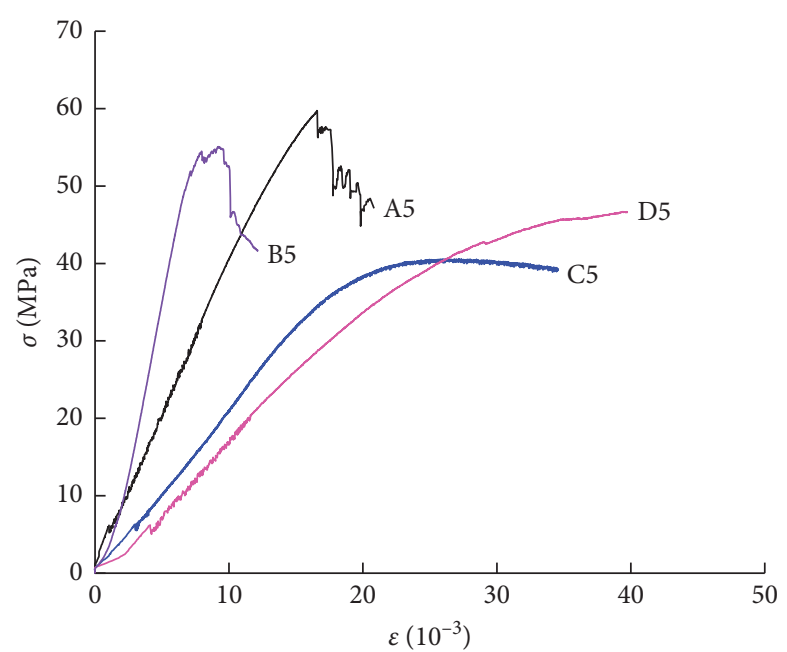

(b)

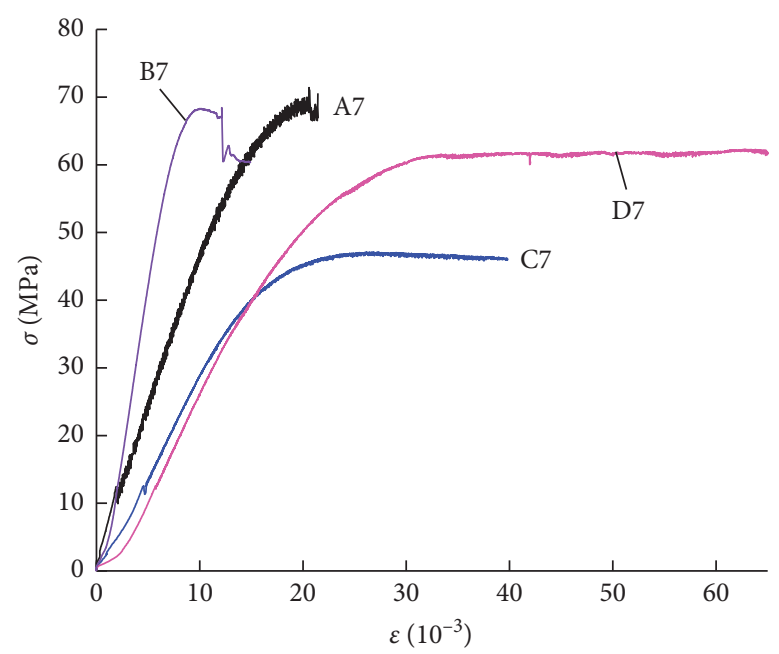

(d)

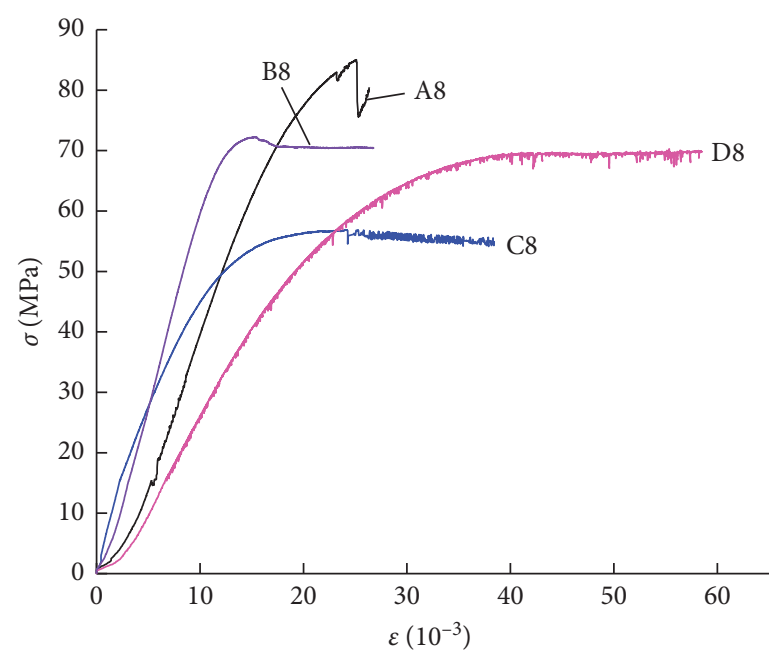

(e)

FIGURE 10: Stress-strain curves of the specimens under the same confining pressure and different water content conditions. . (a) $\sigma_{3}=3 \mathrm{MPa}$. (b) $\sigma_{3}=6 \mathrm{MPa}$. (c) $\sigma_{3}=9 \mathrm{MPa}$. (d) $\sigma_{3}=12 \mathrm{MPa}$. (e) $\sigma_{3}=15 \mathrm{MPa}$. 


$$
\theta_{t}=\frac{2 P}{\pi D H}
$$

where $\sigma_{t}$ is tensile strength $(\mathrm{MPa}), P$ is the failure load $(\mathrm{kN})$, $D$ is the diameter of the sample $(\mathrm{mm})$, and $H$ is the thickness (mm).

According to formula (6), the splitting tensile strength of each group of samples under different water content conditions is calculated, as listed in Table 3.

It can be observed in Table 3 that the tensile strength of the natural sample is the largest, with the average value of 3.85 $\mathrm{MPa}$. The tensile strength of the water saturated sample follows, with an average value of $1.48 \mathrm{MPa}$. The tensile strength of the high-temperature dehydrated sample is the smallest, with an average value of $0.40 \mathrm{MPa}$, which is $89.6 \%$ lower than that of the natural sample, and the tensile strength of this group of samples is more discrete.

The stress-strain curve of each group of samples in the Brazilian disc splitting test is plotted as shown in Figure 11. The tensile splitting failure process of the natural, saturated, and high-temperature dehydrated samples can be divided into four stages: compaction, elastic deformation, plastic deformation, and failure. When the natural and saturated samples reach the peak values of tensile strength, they drop instantly, and the samples show obvious brittle failure. However, the high-temperature dehydrated sample shows the characteristics of split during the splitting process and the plastic deformation period becomes significantly longer. When the load reaches the peak value, it does not drop rapidly and the sample shows certain plastic failure characteristics. The above phenomena indicate that after hightemperature dehydration, physical and chemical degradation occur within the sample, the intermolecular forces inside the particles weaken, the brittleness weakens, plasticity increases, and sample shows obvious plastic softening characteristics.

3.3. Failure Characteristics. Figures 12 and 13 show the failure modes of uniaxial and triaxial compression of each group of samples, respectively.

In Figures 12 and 13, it can be observed that the failure mode of the high-strength gypsum powder remolded sample is not directly related to the confining pressure, but it is related to the water content: the less the water content, the more complex the failure mode. The failure characteristics of the saturated samples are not obvious, and the failure characteristics of natural samples are similar to those of the $45^{\circ} \mathrm{C}$ dehydrated samples. Most of the samples show shear or shear-tensile failure. The shear plane begins from the edge of the end face of the sample and exhibits the typical diagonal shear failure. Some of the samples cracked at the end of the specimen and showed tensile failure. However, the projection of the entire failure surface on the horizontal plane covered the entire specimen's cross section. The appearance of individual specimens also shows $Y$-shear failure in the two shear planes. The controlled shear fracture surface has a fine powdery substance with obvious friction marks, whereas the tensile fracture surface is fresh.
The failure characteristics of the high-temperature dehydrated samples are different from those of the natural and $45^{\circ} \mathrm{C}$ dehydrated samples. After the uniaxial and triaxial tests, these samples have completely broken. In addition to local shear failure, most of these specimens also have a horizontal fracture surface perpendicular to the loading direction, which can be explained by the fact that the porosity of this group of specimens increases significantly after $220^{\circ} \mathrm{C}$ dehydration, reaching more than $25.7 \%$. Under the condition of triaxial compression, the specimens have large elastic and plastic deformation when they are damaged. Once the stress exceeds the peak value, the axial load will be unloaded at the end of the test, and some materials with high strength will not yield to failure. The recovery deformation will exceed the ultimate tensile strain of the material, resulting in a horizontal tensile fracture surface perpendicular to the loading direction.

3.4. Analysis of Mineral Composition. Table 4 lists the main mineral crystal components obtained from the X-ray diffraction test of the high-strength gypsum powder remolded samples under different water content states.

Figure 14 shows the diffraction patterns of each group of samples in different water content states.

It can be observed in Table 4 and Figure 14 that the main mineral components of gypsum are $\mathrm{CaSO}_{4} \cdot 0.5 \mathrm{H}_{2} \mathrm{O}$ and $\mathrm{Ca}\left(\mathrm{SO}_{4}\right)$, with contents of $69 \%$ and $31 \%$, respectively. $\mathrm{CaSO}_{4} \cdot 0.5 \mathrm{H}_{2} \mathrm{O}$ is composed of calcium sulfate crystal with 0.5 crystal water, the maximum diffraction intensity of $\mathrm{CaSO}_{4} \cdot 0.5 \mathrm{H}_{2} \mathrm{O}$ is $812.2 \mathrm{cts}$, and the cumulative diffraction intensity of the main mineral crystal is $2444.75 \mathrm{cts}$. The cumulative diffraction intensity refers to the sum of the diffraction intensities of the main mineral crystals measured at different diffraction angles of the gypsum rock. The main mineral composition of the natural sample prepared after pouring of the gypsum powder is $\mathrm{CaSO}_{4} \cdot 2 \mathrm{H}_{2} \mathrm{O}$ and $\mathrm{Ca}$ $\left(\mathrm{SO}_{4}\right) \cdot\left(\mathrm{H}_{2} \mathrm{O}\right)_{2}$, with contents of $51 \%$ and $49 \%$, respectively, while $\mathrm{Ca}\left(\mathrm{SO}_{4}\right)$ disappears. There are two crystal compositions of calcium sulfate in $\mathrm{CaSO}_{4} \cdot 2 \mathrm{H}_{2} \mathrm{O}$, the maximum diffraction intensity of $\mathrm{CaSO}_{4} \cdot 2 \mathrm{H}_{2} \mathrm{O}$ is $293.27 \mathrm{cts}$, and the cumulative diffraction intensity of the main mineral crystal is $1381.13 \mathrm{cts}$. After $45^{\circ} \mathrm{C}$ dehydration for $48 \mathrm{~h}$, the main mineral components of the natural sample are $\mathrm{CaSO}_{4} \cdot 2 \mathrm{H}_{2} \mathrm{O}$ and $\mathrm{SiO}_{2}$, with contents of $96 \%$ and $4 \%$, respectively. $\mathrm{Ca}\left(\mathrm{SO}_{4}\right)\left(\mathrm{H}_{2} \mathrm{O}\right)_{2}$ disappears and $\mathrm{SiO}_{2}$ is produced. $\mathrm{CaSO}_{4} \cdot 2 \mathrm{H}_{2} \mathrm{O}$ is composed of two crystal water calcium sulfate crystals, the maximum diffraction intensity of $\mathrm{CaSO}_{4} \cdot 2 \mathrm{H}_{2} \mathrm{O}$ is $150.74 \mathrm{cts}$, and the cumulative diffraction intensity of the main mineral crystals is $810.73 \mathrm{cts}$. The main mineral composition of the natural sample after water saturation is changed into $\mathrm{CaSO}_{4} \cdot 2 \mathrm{H}_{2} \mathrm{O}$ and $\mathrm{CaSO}_{4}\left(\mathrm{H}_{2} \mathrm{O}\right)_{2}$, with contents of $81 \%$ and $19 \%$, respectively. The maximum diffraction intensity of $\mathrm{CaSO}_{4} \cdot 2 \mathrm{H}_{2} \mathrm{O}$ is $253.8 \mathrm{cts}$, and the cumulative diffraction intensity of the main mineral crystal is 1243.03 cts. The main mineral composition of the natural sample after $220^{\circ} \mathrm{C}$ high-temperature dehydration is changed into $\mathrm{CaSO}_{4} \cdot 0.5 \mathrm{H}_{2} \mathrm{O}$ and $\mathrm{CaSO}_{4}\left(\mathrm{H}_{2} \mathrm{O}\right)_{2}$, with contents of $61 \%$ and $39 \%$, respectively. The maximum 


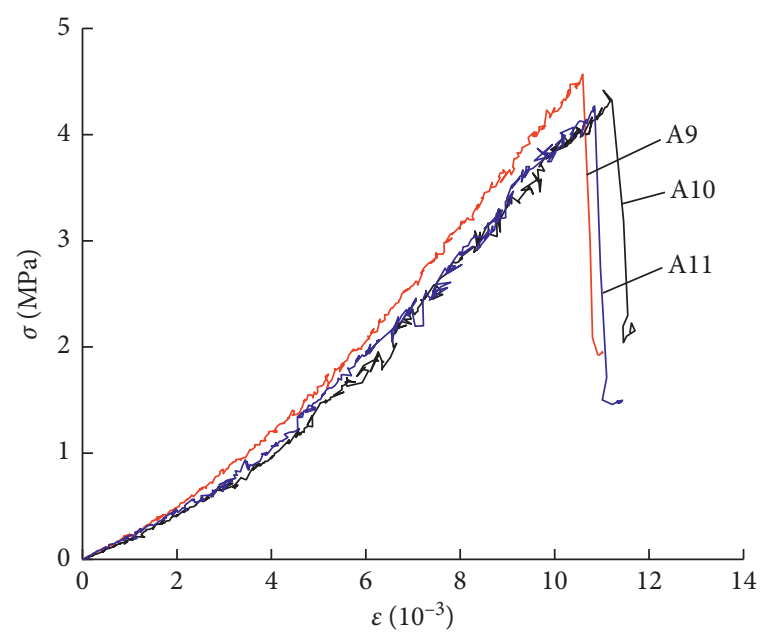

(a)

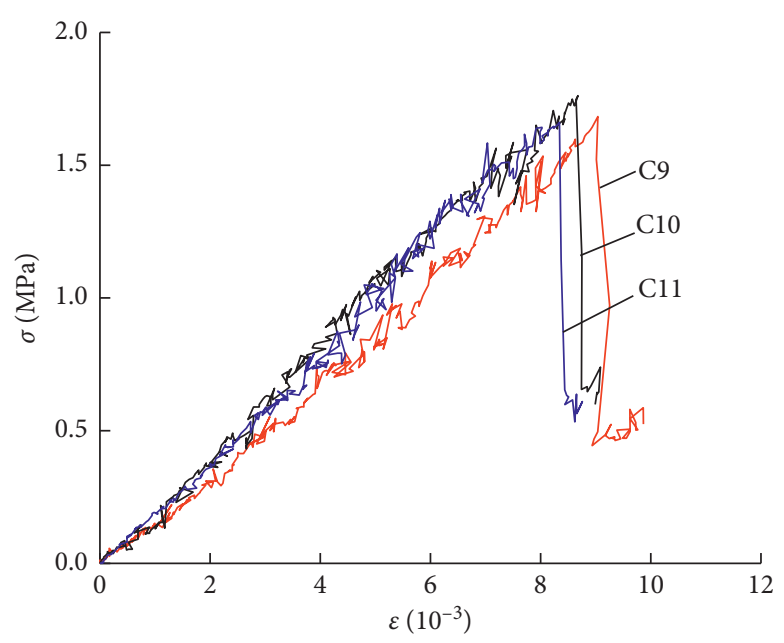

(b)

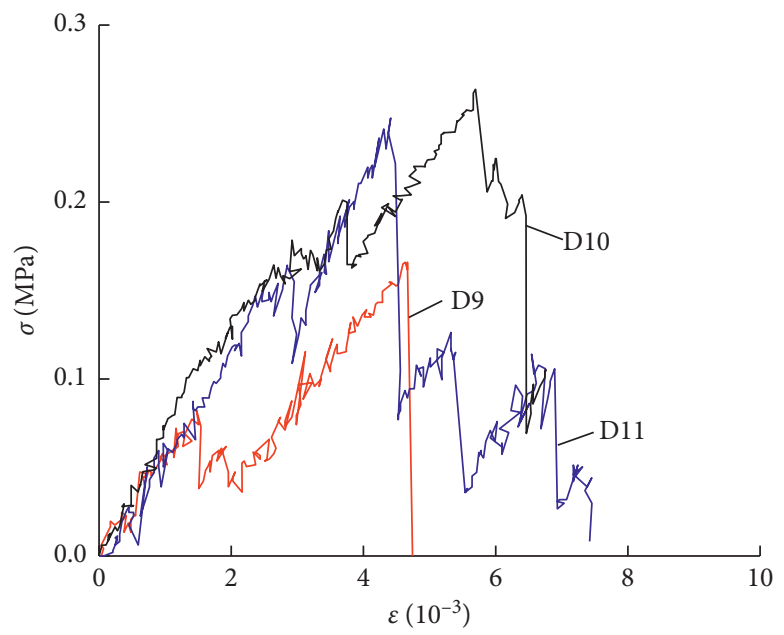

(c)

FIGURE 11: Stress-strain curve of each group of specimens in the Brazilian split test. (a) Natural. (b) Water saturation. (c) High-temperature dehydration at $220^{\circ} \mathrm{C}$.

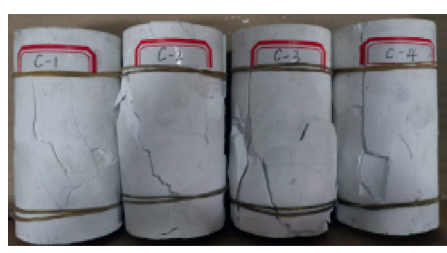

(a)

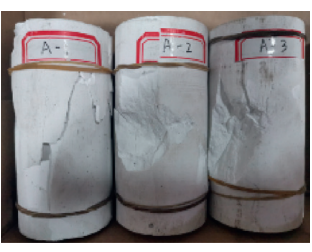

(b)

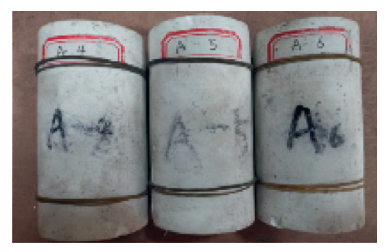

(c)

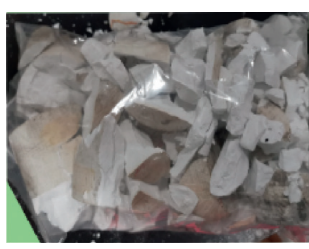

(d)

FiguRE 12: Failure modes of uniaxial compression of each group of samples. (a) Natural. (b) Dehydration at $45^{\circ} \mathrm{C}$. (c) Water saturation. (d) High-temperature dehydration at $220^{\circ} \mathrm{C}$.

diffraction intensity of $\mathrm{CaSO}_{4} \cdot 0.5 \mathrm{H}_{2} \mathrm{O}$ is $85.61 \mathrm{cts}$, and the cumulative diffraction intensity of the main mineral crystal is $626.86 \mathrm{cts}$. The above analysis shows that the calcium sulfate disappears and the water content increases after the high-strength gypsum powder is poured into the remolded sample, and the main mineral composition of the water saturated sample is the same as that of the natural sample.
After $45^{\circ} \mathrm{C}$ dehydration for $48 \mathrm{~h}$, the sample begins to release structured water and generates a small amount of $\mathrm{SiO}_{2}$, but the dehydration rate is slow. After $220^{\circ} \mathrm{C}$ hightemperature dehydration, $\mathrm{CaSO}_{4} \cdot 0.5 \mathrm{H}_{2} \mathrm{O}$ continues to dehydrate and becomes soluble $\mathrm{CaSO}_{4}$, but the $\mathrm{CaSO}_{4}$ generated at $220^{\circ} \mathrm{C}$ absorbs water in the air and becomes $\mathrm{CaSO}_{4} \cdot 0.5 \mathrm{H}_{2} \mathrm{O}$ and $\mathrm{CaSO}_{4} \cdot 2 \mathrm{H}_{2} \mathrm{O}$. 


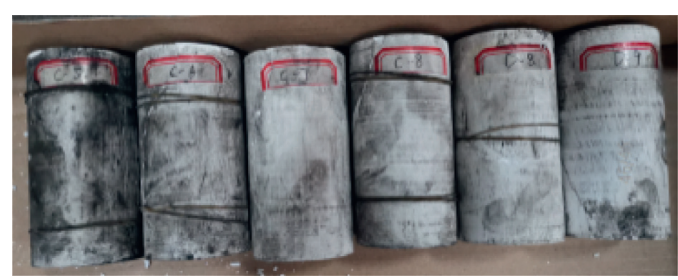

(a)

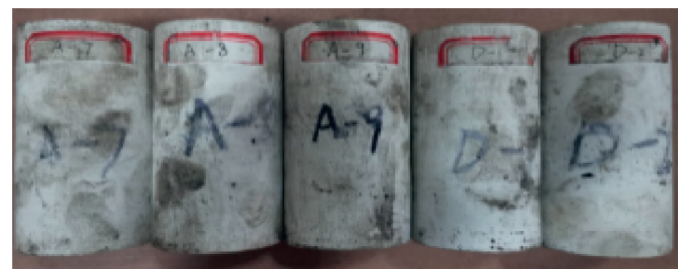

(c)

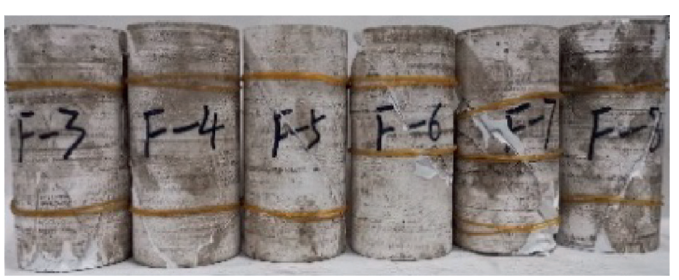

(b)

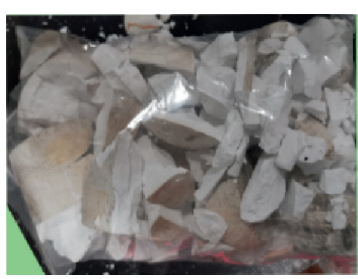

(d)

Figure 13: Failure modes of triaxial compression of each group of samples. (a) Natural. (b) Dehydration at $45^{\circ} \mathrm{C}$. (c) Water saturation. (d) High-temperature dehydration at $220^{\circ} \mathrm{C}$.

TABLE 4: The main mineral composition of gypsum powder remolded samples in different states.

\begin{tabular}{llcc}
\hline Temperature $\left({ }^{\circ} \mathrm{C}\right)$ & Compound name & Chemical formula & Composition (\%) \\
\hline \multirow{2}{*}{ Gypsum } & Calcium sulfate hydrate & $\mathrm{CaSO}_{4} \cdot 0.5 \mathrm{H}_{2} \mathrm{O}$ & 69 \\
& Calcium sulfate & $\mathrm{Ca}\left(\mathrm{SO}_{4}\right)$ & 31 \\
Natural & Calcium sulfate hydrate & $\mathrm{CaSO}_{4} \cdot 2 \mathrm{H}_{2} \mathrm{O}$ & 51 \\
& Calcium sulfate hydrate & $\mathrm{Ca}\left(\mathrm{SO}_{4}\right)\left(\mathrm{H}_{2} \mathrm{O}\right)_{2}$ & 49 \\
$45^{\circ} \mathrm{C}$ dehydration & Calcium sulfate hydrate & $\mathrm{Ca}\left(\mathrm{SO}_{4}\right)\left(\mathrm{H}_{2} \mathrm{O}\right)_{2}$ & 96 \\
& Silicon oxide & $\mathrm{SiO}_{2}$ & 4 \\
Water saturation & Calcium sulfate hydrate & $\mathrm{CaSO}_{4} \cdot 2 \mathrm{H}_{2} \mathrm{O}$ & 81 \\
& Calcium sulfate hydrate & $\mathrm{CaSO}_{4}\left(\mathrm{H}_{2} \mathrm{O}\right)_{2}$ & 19 \\
$220^{\circ} \mathrm{C}$ high-temperature dehydration & Calcium sulfate hydrate & $\mathrm{CaSO}_{4} \cdot 0.5 \mathrm{H}_{2} \mathrm{O}$ & 61 \\
& Calcium sulfate hydrate & $\mathrm{CaSO}_{4} \cdot 2 \mathrm{H}_{2} \mathrm{O}$ & 39 \\
\hline
\end{tabular}

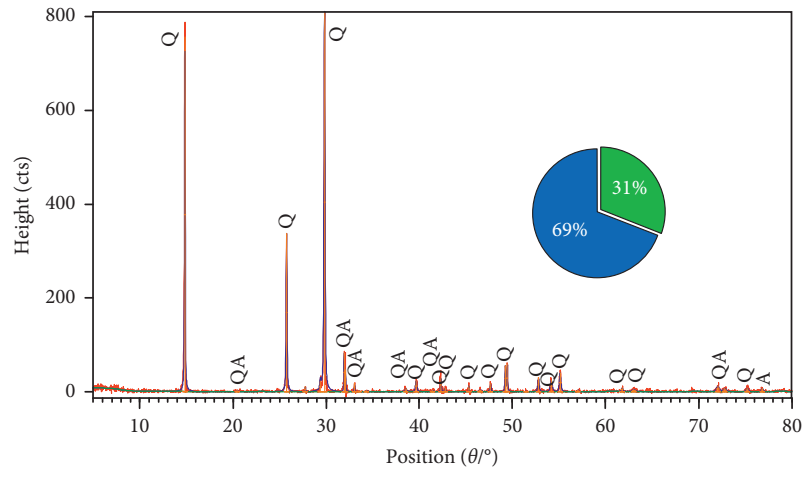

Q: calcium sulfate hydrate/ $\mathrm{CaSO}_{4} \cdot 0.5 \mathrm{H}_{2} \mathrm{O}$ A: calcium sulfate/ $\mathrm{Ca}\left(\mathrm{SO}_{4}\right)$

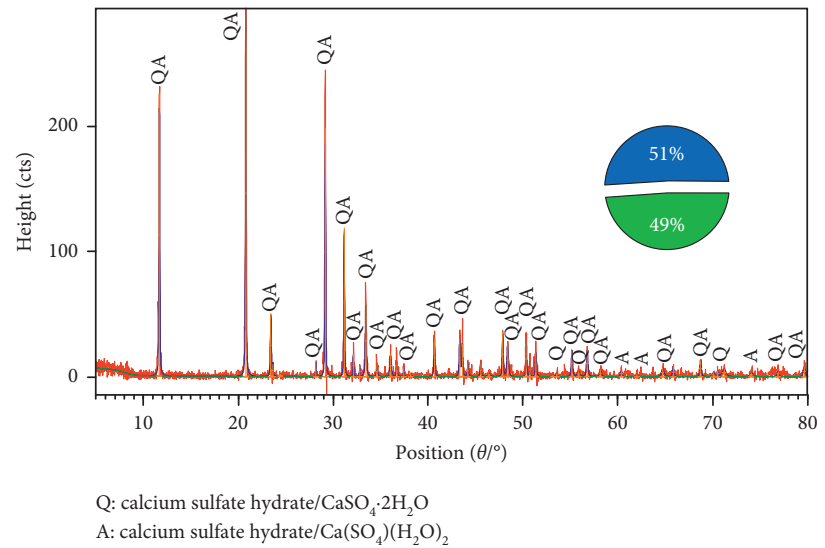

(b)

FIgURE 14: Continued. 


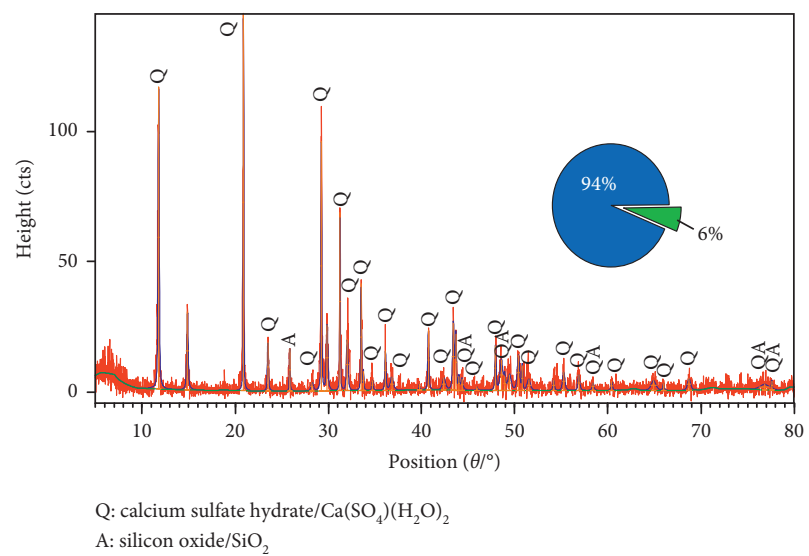

(c)

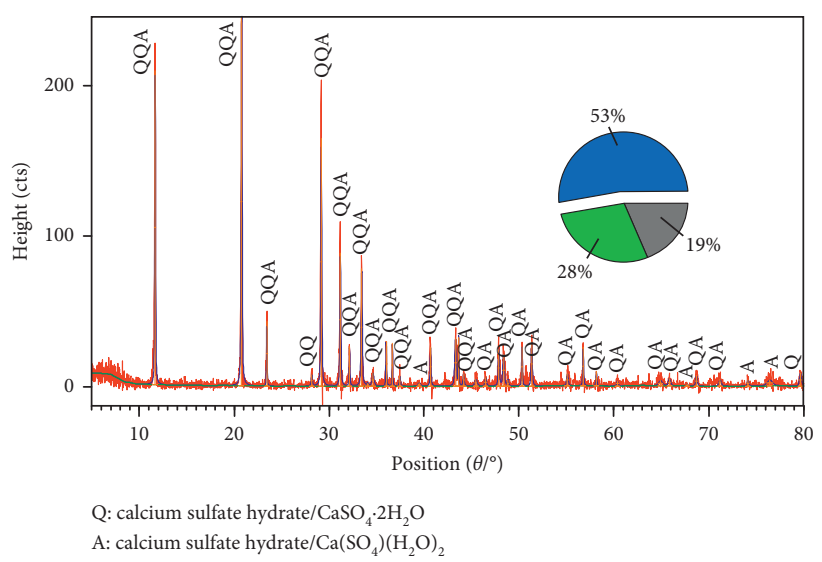

(d)

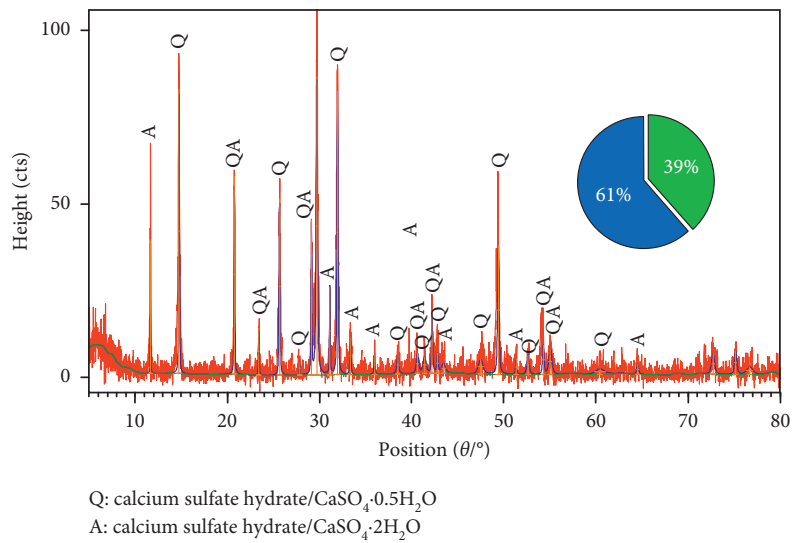

(e)

Figure 14: X-ray diffraction pattern of each group of samples. (a) Gypsum. (b) Natural sample. (c) Dehydrated sample at $45^{\circ} \mathrm{C}$. (d) Water saturated sample. (e) High-temperature dehydrated sample at $220^{\circ} \mathrm{C}$.

\section{Discussion}

The above analysis shows that water saturation and dehydration have certain degradation effect on the physical and mechanical properties of high-strength gypsum powder remolded samples. To further explore the influence mechanism of water saturation and dehydration on the mechanical properties of remolded samples, the microstructure of each group of samples was scanned with the FEI Quanta 250 FEG-SEM. Figure 15 shows the scanning results at a magnification of 3000 times.

It can be observed that the internal structure of the remolded sample under natural conditions is homogeneous and compact, the particles are dense, the crystal fracture is smooth and flat, the edges and corners are sharp and obvious, and the local part is massive, as shown in Figure 15(a). After $45^{\circ} \mathrm{C}$ dehydration for $48 \mathrm{~h}$, the internal microparticle structure of the sample changed significantly, and a loose flocculent structure begins to form on the surface, some particles begin to become loose, the crystal fracture is fuzzy, some crystals appear as prismatic, and micropores begin to appear, as shown in Figure 15(b). There is more dehydrate gypsum in the saturated sample, and the homogeneous and compact edges and corners of the sample are not obvious, as shown in Figure $15(\mathrm{c})$. After $220^{\circ} \mathrm{C}$ high-temperature dehydration for $12 \mathrm{~h}$, a large number of disordered prismatic crystals are formed inside the sample, microcracks are distributed among the crystals, and some crystals are broken. The fracture surface is clear, and the number of micropores is significantly increased, as shown in Figure 15(d). The above analysis shows that the crystal water in the natural sample has at least two combined states, that is, structural and zeolite water [30].

During the heating process of gypsum dehydrate $\left(\mathrm{CaSO}_{4} \cdot 2 \mathrm{H}_{2} \mathrm{O}\right)$ at a certain temperature, the gypsum crystal will absorb heat to overcome the van der Waals force and disconnect the covalent bond, and the molecular force of $\mathrm{CaSO}_{4}$ will be weakened. Thus, the structural water will gradually change from the main crystal structure to the water from the hemihydrate gypsum $\left(\mathrm{CaSO}_{4} \cdot 0.5 \mathrm{H}_{2} \mathrm{O}\right)$, while the zeolite water will remain in the hemihydrate gypsum $\left(\mathrm{CaSO}_{4} \cdot 0.5 \mathrm{H}_{2} \mathrm{O}\right)$. Only when heating to a certain temperature and time, can the hemihydrate gypsum $\left(\mathrm{CaSO}_{4} \cdot 0.5 \mathrm{H}_{2} \mathrm{O}\right)$ be completely transformed into anhydrous gypsum $\left(\mathrm{CaSO}_{4}\right)$. After dehydration, there will be a vacancy in the original crystal water position. In this study, the removed microcrystal 


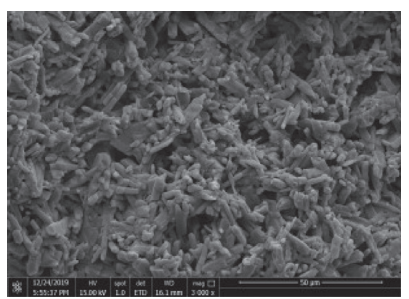

(a)

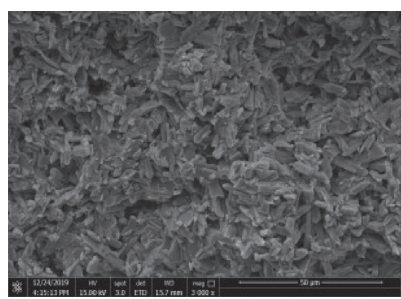

(b)

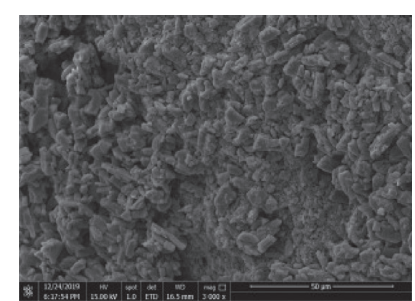

(c)

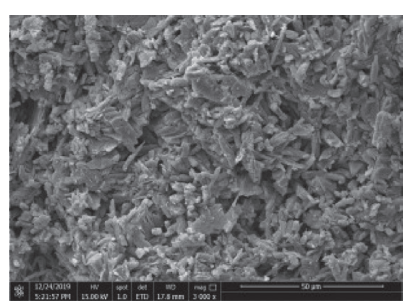

(d)

Figure 15: Scanning results at 3000x magnification. (a) Natural. (b) $45^{\circ} \mathrm{C}$ dehydration. (c) Water saturation. (d) High-temperature dehydration.

water is used to characterize the macro- and microcracks of the sample. Although this is not accurate, it can characterize the internal macro- and microcracks of the remolded sample to a certain extent. With the increase in high-temperature dehydration time, the crystal structure and shape of the gypsum rock change gradually, and the number of microcracks and holes in the sample increases gradually. With the expansion and penetration of cracks, the width, length, and coverage of cracks increase gradually and macrodamage develops continuously, resulting in the continuous deterioration of the physical and mechanical properties.

\section{Conclusion}

In order to study the physical and mechanical properties of gypsum-like rock samples, four sets of samples under different water conditions were tested by ultrasonic, uniaxial compression, conventional triaxial compression, Brazilian splitting, X-ray diffraction, and scanning electron microscope. The following conclusions are drawn:

(1) The density of the water saturated sample and the longitudinal wave velocity of the natural sample are the highest. Both the water saturation and dehydration conditions have a weakening effect on the remolded sample of high-strength gypsum powder.

(2) The peak intensity of the sample gradually increases with the increase of confining pressure, and the relationship between the peak intensity and confining pressure of the sample conforms to the Coulomb strength criterion. After high-temperature dehydration, the sample showed obvious plastic softening characteristics.

(3) The cohesion and internal friction angle of the sample are closely related to the water content. The cohesion is the largest in the $45^{\circ} \mathrm{C}$ dehydrated sample and the internal friction angle is the smallest in the saturated sample, whereas the cohesion is the smallest and internal friction is the largest in the high-temperature dehydrated sample.

(4) The characteristics of failure for the natural and $45^{\circ} \mathrm{C}$ dehydrated samples are almost the same and most samples show shear or shear-tensile failure. The shear plane begins at the edge of the end face of the sample and exhibits a typical diagonal shear failure. The high-temperature dehydrated samples are completely broken under uniaxial and triaxial compression conditions.

(5) After high-strength gypsum powder was used to make the remolded sample, the calcium sulfate disappeared, the water content increased, and the main mineral components of the natural and saturated samples were the same. After dehydration at $45^{\circ} \mathrm{C}$, the sample began to release structural water and generate $\mathrm{SiO}_{2}$. After high-temperature dehydration, the hemihydrate gypsum continued to dehydrate and become soluble anhydrous gypsum.

\section{Data Availability}

All included experimental data are absolutely reliable and the datasets supporting this article have been uploaded as part of the electronic supplementary material.

\section{Conflicts of Interest}

The authors declare no conflicts of interest.

\section{Acknowledgments}

This work was supported by National Natural Science Foundation of China (no. 51974104), Henan Science and Technology Research Project (182102210317), and Henan University Basic Research Business Expense Special Funds Subsidy Project (NSFRF180402).

\section{Supplementary Materials}

The original data are given in the supplementary material file. (Supplementary Materials)

\section{References}

[1] S. Azam, "Study on the geological and engineering aspects of anhydrite/gypsum transition in the Arabian gulf coastal deposits," Bulletin of Engineering Geology and the Environment, vol. 66, no. 2, pp. 177-185, 2007.

[2] X. M. Liu, X. W. Jiang, C. X. Chen et al., "Study of creep characteristics of gypsum rock in natural and saturated states," Rock and Soil Mechanics, vol. 38, no. 1, pp. 277-283, 2017.

[3] F. Chen, S. C. Wu, S. Ren, and Z. Y. Li, "Failure mode and time-dependent reliability model of tunnel lining structure 
built in gypsum rock," Chinese Journal of Engineering, vol. 39, no. 11, pp. 1626-1633, 2017.

[4] K. Z. Xia, C. X. Chen, X. G. Song, X. M. Liu, and Y. C. Zhou, "Analysis of catastrophic failure mechanism of roof bed in gypsum mines induced by relative humidity," Rock and Soil Mechanics, vol. 39, no. 2, pp. 589-597, 2018.

[5] C. Auvray, F. Homand, and C. Sorgi, "The aging of gypsum in underground mines," Engineering Geology, vol. 74, no. 3-4, pp. 183-196, 2004.

[6] C. Auvray, F. Homand, and D. Hoxha, "The influence of relative humidity on the rate of convergence in an underground gypsum mine," International Journal of Rock Mechanics and Mining Sciences, vol. 45, no. 8, pp. 1454-1468, 2008.

[7] W. G. Liang, C. D. Zhang, H. B. Gao, S. G. Xu, and X. Q. Yang, "Experimental study of mechanical properties of gypsum saturated in brine," Chinese Journal of Rock Mechanics and Engineering, vol. 29, no. 6, pp. 1156-1162, 2010.

[8] H. B. Gao, W. G. Liang, X. Q. Yang, C. D. Zhang, G. Y. Yue, and P. Zhang, "Experimental study of mechanical property of gypsum rock soaked in hot saturated brine," Chinese Journal of Rock Mechanics and Engineering, vol. 30, no. 5, pp. 935943, 2011.

[9] J. H. Deng, X. C. Huang, and Y. J. Li, “Experimental research on the mechanical properties of gypsum breccia with different water content," Journal of Shanghai Jiaotong University, vol. 15, no. 5, pp. 250-256, 2010.

[10] W. D. Yu, W. G. Liang, Y. M. Yu, and X. Q. Yang, "Study on gypsum mesoscopic structure derivation under different concentrations of salt at room temperature," Journal of Taiyuan Technology University, vol. 44, no. 4, pp. 470-473, 2013.

[11] C. Evju and S. Hansen, "The kinetics of ettringite formation and dilatation in a blended cement with beta-hemihydrate and anhydrite as calcium sulfate," Journal of Structural Biology, vol. 35, no. 12, pp. 2310-2312, 2004

[12] Y. H. Huang, Y. Pan, and S. H. Tang, "A study on triaxial compression mechanical tests of anhydrite," China Nonmetallic Mineral Industry Guide, vol. 72, no. 6, pp. 34-36, 2008.

[13] L. J. Yu, W. T. Zhang, M. Fan, W. X. Liu, and R. D. Peng, "Triaxial compression test and study on high temperature phase transition characteristics of paste rock," Rock and Soil Mechanics, vol. 33, no. 11, pp. 3318-3322, 2012.

[14] C. D. Su, S. J. Wei, C. B. Xu, and F. Q. Su, "Experimental study on physico-mechanical effects of high temperature dehydrated gypsum rock," Journal of Rock Mechanics and Engineering, vol. 38, no. 2, pp. 254-266, 2019.

[15] X. M. Shi, B. G. Liu, and J. Xiao, "Determination method of the ratio of cement and gypsum cementing similar materials," Rock and Soil Mechanics, vol. 36, no. 5, pp. 1357-1362, 2015.

[16] S. Cao, E. Yilmaz, W. Song, E. Yilmaz, and G. Xue, "Loading rate effect on uniaxial compressive strength behavior and acoustic emission properties of cemented tailings backfill," Construction and Building Materials, vol. 213, pp. 313-324, 2019.

[17] D. Y. Jiang, J. W. Zhang, J. Chen et al., "Research on softening law of insoluble interlayer during salt cavern building," Journal of Rock Mechanics and Engineering, vol. 33, no. 5, pp. 865-873, 2014.

[18] D. Y. Jiang, T. Ren, J. Chen et al., "Experimental study of mechanical characteristics of molded salt rock with weak interlayer," Chinese Journal of Rock Mechanics and Engineering, vol. 31, no. 9, pp. 1797-1803, 2012.
[19] S. Cao, E. Yilmaz, G. L. Xue, and W. Song, "Assessment of acoustic emission and triaxial mechanical properties of rockcemented tailings matrix composites," Advences in Materials Science and Engineering, vol. 201911 pages, 2019.

[20] Y. Li, H. M. Yu, K. Li et al., "Laboratory study on degradation of gypsum rock with dry-wet cycles," Journal of Yangtze River Scientific Research Institute, vol. 34, no. 3, pp. 63-66, 2017.

[21] S. C. Wu, W. Han, F. Chen et al., "Optimisation of buffer layer thickness in gypsum rock tunnel based on swelling constitutive model," Rock and Soil Mechanics, vol. 39, no. 4, pp. 1182-1190, 2018.

[22] Y. C. Zhou, C. X. Chen, X. M. Liu et al., "Experimental study on mechanical properties of water- softening gypsum rock in jingmen," Rock and Soil Mechanics, vol. 38, no. 10, pp. 2847-2854, 2017.

[23] C. Chiara, B. Sabrina, and C. Cesare, "Comparison of laboratory and field electrical resistivity measurements of a gypsum rock for mining prospection applications," International Journal of Mining Science and Technology, vol. 29, no. 6, pp. 841-849, 2019.

[24] S. Mohammadhossein and J. Stanley, "Vitton: analysis of drying and saturating natural gypsum samples for mechanical testing," Journal of Rock Mechanics and Geotechnical Engineering, vol. 22, no. 2, pp. 217-227, 2019.

[25] M. Sadeghiamirshahidi and S. J. Vitton, "Mechanical properties of Michigan basin's gypsum before and after saturation," Journal of Rock Mechanics and Geotechnical Engineering, vol. 11, no. 4, pp. 739-748, 2019.

[26] Coal Industry Ministry of the People's Republic of China, Measuring Methods of Physico-Mechanical Properties for Coal and Rock, Standards Press of China, Beijing, China, 1988.

[27] S. Wei, Y. Yang, C. Su, S. R. Cardosh, and H. Wang, "Experimental study of the effect of high temperature on the mechanical properties of coarse sandstone," Applied Sciences, vol. 9, no. 12, 2019.

[28] C. D. Su, S. J. Wei, Y. S. Yang, and B. D. Qin, “Analysis of strength and conventional triaxial compression deformation characters of coarse sandstone after high temperature," Chinese Journal of Rock Mechanics and Engineering, vol. 34, no. 1, pp. 2792-2799, 2015.

[29] Y. F. Wang, H. Su, L. P. Wang, H. Z. Jiao, and Z. Li, "Study on the difference of deformation and strength characteristics of three kinds of sandstone," Journal of China Coal Society, vol. 45, no. 4, pp. 1367-1374, 2019.

[30] Y. L. Zhao and L. Y. Xu, Technical Question and Answers of Gypsum Application, China Building Materials Press, Beijing, China, 2016. 